Sam J. Basham

W. G. Rieder

J. H. Stang

H. T. Gruber

B. P. Fairand

October 10, 1964 


\section{DISCLAIMER}

This report was prepared as an account of work sponsored by an agency of the United States Government. Neither the United States Government nor any agency Thereof, nor any of their employees, makes any warranty, express or implied, or assumes any legal liability or responsibility for the accuracy, completeness, or usefulness of any information, apparatus, product, or process disclosed, or represents that its use would not infringe privately owned rights. Reference herein to any specific commercial product, process, or service by trade name, trademark, manufacturer, or otherwise does not necessarily constitute or imply its endorsement, recommendation, or favoring by the United States Government or any agency thereof. The views and opinions of authors expressed herein do not necessarily state or reflect those of the United States Government or any agency thereof. 


\section{DISCLAIMER}

Portions of this document may be illegible in electronic image products. Images are produced from the best available original document. 
ABSTRACT . . . . . . . . . . . . . . . . . . . . . . . . 1

INTRODUCTION . . . . . . . . . . . . . . . . . . . . . . . . . . . . 1

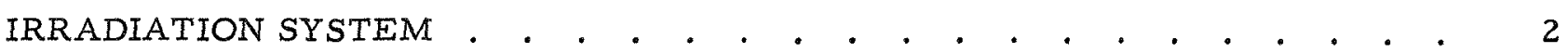

Facility at Reactor. . . . . . . . . . . . . . . . . . . . . 2

Specimen Assemblies . . . . . . . . . . . . . . . . . . . . 5

$\mathrm{HF}-1$ Assembly . . . . . . . . . . . . . . . . . 6

$\mathrm{HF}-2$ Assembly . . . . . . . . . . . . . . . . . 8

HF-3 Assembly . . . . . . . . . . . . . . . . . . 11

$\mathrm{HF}-4$ Assembly . . . . . . . . . . . . . . . . . . 11

FLUX-LEVEL CONSIDERATIONS AND MEASUREMENTS . . • • . . . . 15

Background . . . . . . . . . . . . . . . . . . . . 15

Measurements Techniques . . . . . . . . . . . . . 15

Mock-up Data . . . . . . . . . . . . . . . . . . . . 19

Neutron Spectra . . . . . . . . . . . . . . . . 19

Neutron Flux Distributions . . . . . . . . . . . . . . 22

Gamma . . . . . . . . . . . . . . . . . 22

IN-PILE OPERATION . • . . . . . . . . . . . . . . . . . . 25

Experiment $\mathrm{HF}-1$. . . . . . . . . . . . . . . . . 25

Operation . . . . . . . . . . . . . . . . . 25

Temperature Levels. . . . . . . . . . . . . . 26

Vacuum Levels . . . . . . . . . . . . . . . . . . 27

Electrical Measurements . . . . . . . . . . . . 27

Experiment $\mathrm{HF}-2$. . . . . . . . . . . . . . . . 28

Operation . . . . . . . . . . . . . . . . . . 28

Temperature Levels. . . . . . . . . . . . . . . . 28

Vacuum Levels . . . . . . . . . . . . . . . . . 28

Electrical Measurements . . . . . . . . . . . . . 28

Experiment $H F-3$. . . . . . . . . . . . . . . . 29

Operation . . . . . . . . . . . . . . . . . 29

Temperature Levels. . . . . . . . . . . . . . . 29

Vacuum Levels . . . . . . . . . . . . . . . . . . 30

Electrical Measurements . . . . . . . . . . . . . 30

Experiment $H F-4$. . . . . . . . . . . . . . . . . . . 31

Operation . . . . . . . . . . . . . . . . 31

Temperature Levels. . . . . . . . . . . . . . . 31

Vacuum Levels . . . . . . . . . . . . . . . . . 32

Electrical Measurements . . . . . . . . . . . . . 32

Summary of Specimen Radiation Exposures. . . . . . . . . . . 34 
TABLE OF CONTENTS

(Continued)

APPENDIX

RADIATION EXPOSURES OF INDIVIDUAL COMPONENTS OF EXPERIMENTS

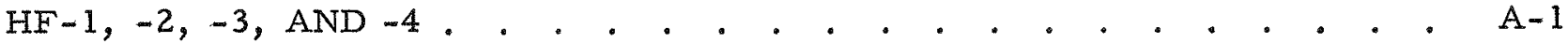




\title{
EXPERIMENTAL TECHNIQUES USED \\ FOR HIGH-TEMPERATURE, VACUUM \\ IRRADIATIONS OF ELECTRICAL \\ COMPONENTS AND MATERIALS
}

Sam J. Basham

W. G. Rieder

J. H. Stang

H. T. Gruber

B. P. Fairand

\section{ABSTRACT}

\begin{abstract}
A group of materials and electrical components was exposed to an integrated fast-neutron exposure of about $1 \times 1019 \mathrm{n} / \mathrm{cm}^{2}$ while in an environment of high vacuum $\left(<10^{-5}\right.$ torr) and high temperature $(600$ to $1100 \mathrm{~F})$ to obtain radiationeffects data for the Atomics International SNAP program. Four separate experiments were conducted; 34 specimens were exposed in the first, 6 specimens in the second, 48 specimens in the third, and 32 specimens in the fourth. Detailed measurements of the nuclear environment were made to aid in the study of radiation damage of the specimens. Significant specimen parameters of the electrical components were measured during the irradiation. These data were transmitted to Atomics International for use in SNAP program systems development.
\end{abstract}

\section{INTRODUCTION}

Under the auspices of Atomics International, Division of North American Aviation, Inc., Battelle is conducting a series of radiation-damage experiments at the Battelle Research Reactor. Part of the program consists of the irradiation of electronic components, instruments, and materials under conditions as follows:

Temperature - 600 to $1100 \mathrm{~F}$

Integrated fast-neutron exposure - in the $1 \times 10^{19} \mathrm{n} / \mathrm{cm}^{2}$ range

Vacuum level - in the $1 \times 10^{-5}$ tor $\mathrm{r}$ range.

The four experiments which are described in this report constitute part of this program. These experiments are designated as HF (high-flux) $-1,-2,-3$, and -4 . Another part of the program consists of in-vacuum irradiations at approximately $150 \mathrm{~F}$ to a total integrated fast-neutron exposure of approximately $1 \times 10^{16} \mathrm{n} / \mathrm{cm}^{2}$. Experiments of this kind have been described in a recent report designated BMI-X-290.

In general, each of the four experiments consisted of the following phases: 
(1) Selection by Atomics International of components to be irradiated in each experiment and the experimental conditions

(2) Reactor mapping to determine flux distribution and gamma exposure rates

(3) Experiment design

(4) Experiment assembly and installation at the reactor using one of the high-vacuum facilities available there

(5) Conduct of experiment, including continuous temperature monitoring of all specimens and periodic monitoring of the performance of some to ascertain damage thresholds and degradation rates as these thresholds were exceeded

(6) Postirradiation evaluation of experiment dosimetry.

This report covers the design, various operating procedures, and specimen radiation levels for the four experiments. Emphas is is placed on the last inasmuch as a significant effort was devoted to dosimetry in order to procure the accurate and detailed information required for interpreting radiation-damage effects. The component performance data that were obtained are not presented in this report. These were forwarded to Atomics International for use in their systems-development tasks for the SNAP program.

While most of the irradiated samples were discarded, a few were subjected to postirradiation examinations at the Battelle Hot Cell Facility. The information was relayed to Atomics International as it was accumulated.

\title{
IRRADIATION SYSTEM
}

\author{
Facility at Reactor
}

Figure 1 illustrates the BRR vacuum facility which was adapted to the requirements of the four irradiation experiments. The modified facility consisted of a test section (8-in. aluminum pipe), a tee-section, a specimen-lead housing (4-in. pipe), an ionization-gage-lead housing (2-1/2 in. pipe), a vacuum line to the reactor pool surface (6-in. pipe), and a pumping unit with a 6-in. liquid-nitrogen cold trap, a 6-in. oil diffusion pump, and a roughing pump. The system vacuum was sensed by two ionization gages located in the vacuum line just upstream from the tee-section and by a gage located just downstream from the diffusion pump.

The entire facility was mounted from the instrument bridge, which could be moved back and forth between the back pool and the irradiation zone at the front face of the reactor core. Figure 2 shows this location. In addition to the horizontal movement, the framework on which the facility was mounted could be moved vertically in order to facilitate the insertion and removal of test subassemblies and the maneuvering of a test section into the core position. 


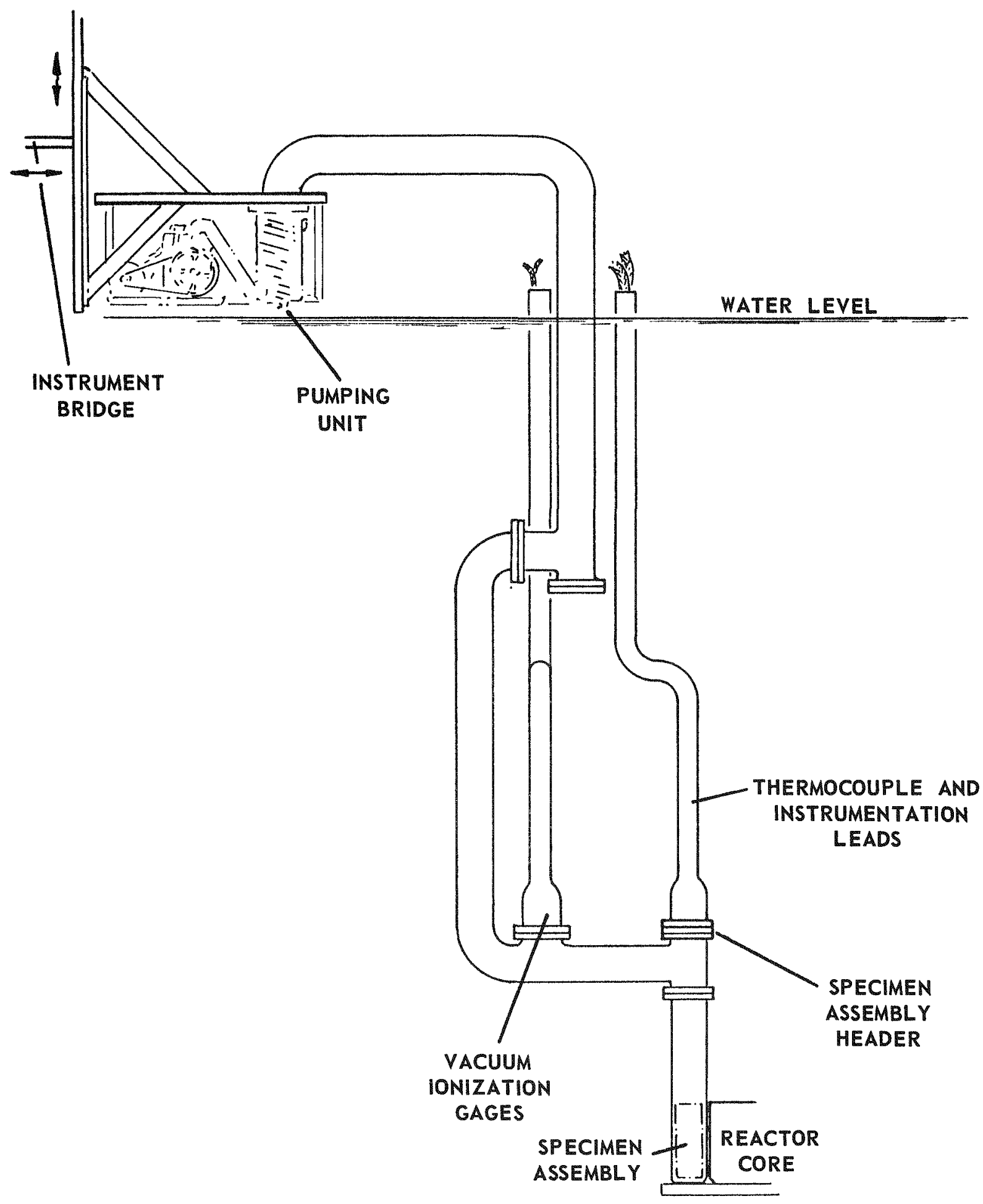

FIGURE 1. VACUUM IRRADIATION FACILITY AT FRONT CORE FACE OF BRR 


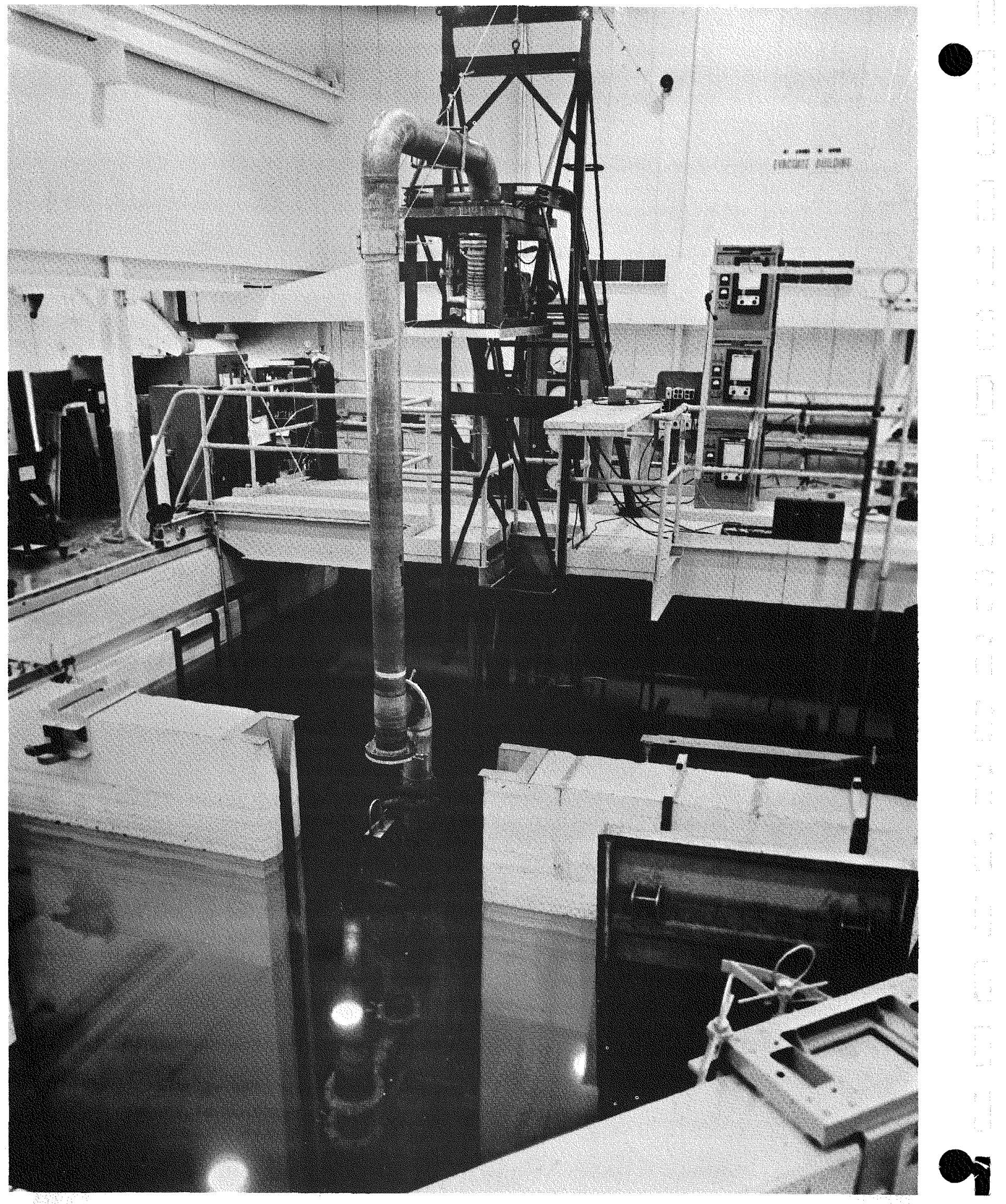

FIGURE 2. INSTRUMENT BRIDGE AND SUPPORT STRUCTURE FOR VACUUM FACILITY 
The piping arrangement allowed a specimen subassembly to be inserted through the upper side of the tee-section. The top-seal plate served as the point of exit of thermocouple and specimen leads from the vacuum chamber and also as a support from which to suspend the specimen assembly. The leads were brought through 9-pin glassto-metal seals, each vacuum sealed to the plate by a small elastomer O-ring held down by a threaded bushing. A large elastomer O-ring was utilized to form the vacuum closure at the water-exposed mating flange surfaces.

The specimen leads were brought to an area where the temperature-recording instrumentation was located.

In addition to the basic irradiation facility, several accessory systems were provided. These included

(1) A circulating water system for specimen cooling

(2) A heat-control system with three separate saturablecore-reactor power supplies

(3) Temperature-recording instrumentation with a capacity of 30 thermocouples.

Specimen Assemblies

The four experiments covered in this report were similar with regard to thermocouplery, auxiliary heating, etc. The following summarizes briefly this aspect of their design.

(1) Each specimen was provided with at least one bare-wire Chromel-Alumel thermocouple for in-pile temperature monitoring. In most cases, the thermocouples were fastened by spot welding or clamping to exposed specimen surfaces. In a few instances, the specimen material precluded this and it was necessary to position a thermocouple junction by inserting it into a small blind hole drilled into the test body. The specimens in the $\mathrm{HF}-2$ experiment and several in the $\mathrm{HF}-4$ experiment were delivered to Battelle with short Chromel-Alumel thermocouples already incorporated into them. The attachment of thermocouples to these was merely a matter of spot welding the integral thermocouples to ChromelAlumel lead-out pairs.

Between the specimen zone and the top seal plate, the thermocouples were protected with porcelain or 60 pex cent $\mathrm{Al}_{2} \mathrm{O}_{3}$ tubing for insulation.

(2) With the exception of the leads for the temperature sensor in Experiment HF-4, all specimen monitoring leads were bare 0.045-in. diameter nickel wire insulated with ceramic tubing. The temperature sensor was provided with platinum leads.

(3) The HF-1, -3 , and -4 assemblies were each provided with one or more sets of circuits (dummy leads) not connected to any component. These 
were utilized to obtain certain correction factors for the interpretation of the various specimen-performance monitorings.

(4) Each specimen assembly (except HF-2) included several independently controlled sheathed auxiliary heaters with a total capacity of from 5 to $9 \mathrm{kw}$. The heaters were positioned between the specimen array and the reactor-water-contacting containment chamber. During the exposure, these heaters had the capability of regulating specimen temperature levels by acting, in essence, as variable-temperature thermal-radiation baffles. Another heater function was that of maintaining the specimen temperatures during reactor-shutdown periods. This shutdown-period maintenance of temperature was routinely accomplished unless precluded by the necessity for equipment maintenance.

(5) Each assembly included a large number of nickel, iron, and aluminum-cobalt dosimeter wires for postirradiation determinations of integrated fluxes. These wires were attached directly to specimens or were enclosed in ceramic tubes and dispersed around the specimen assembly in a uniform-geometry pattern.

Owing to a variety of heat-transfer considerations, the placement of specimens to form an assembly varied considerably among the experiments.

\section{$\underline{H F-1 \text { Assembly }}$}

Figure 3 presents a view of the $\mathrm{HF}-1$ specimen assembly without the surrounding heater coils in place. The assembly included 34 specimens as follows:

15 Inconel-X sheet-type tensile samples joined by nickel-chromium and silver-copper-indium alloy braze

3 Inconel $\mathrm{X}$ tensile bars

14 spools of two distinctly different geometries (each spool having two copper wire coils insulated with an inorganic oxide; Type 304 stainless steel core)

2 Alnico VI magnet assemblies.

The basic specifications for the HF-1 experiment included a specimen temperature level of $800 \mathrm{~F}$ during irradiation. The heat-transfer aspects were complicated by the fact that the specimens were quite massive, were to be gamma heated in the vacuum environment. The only available means of gamma-heat dissipation was by thermal radiation or by conduction through a path attached reliably to a heat sink. It was apparent that the more massive specimens would definitely require the latter since, under even the most optimistic circumstances, thermal radiation would be inadequate to dissipate the gamma heat. 

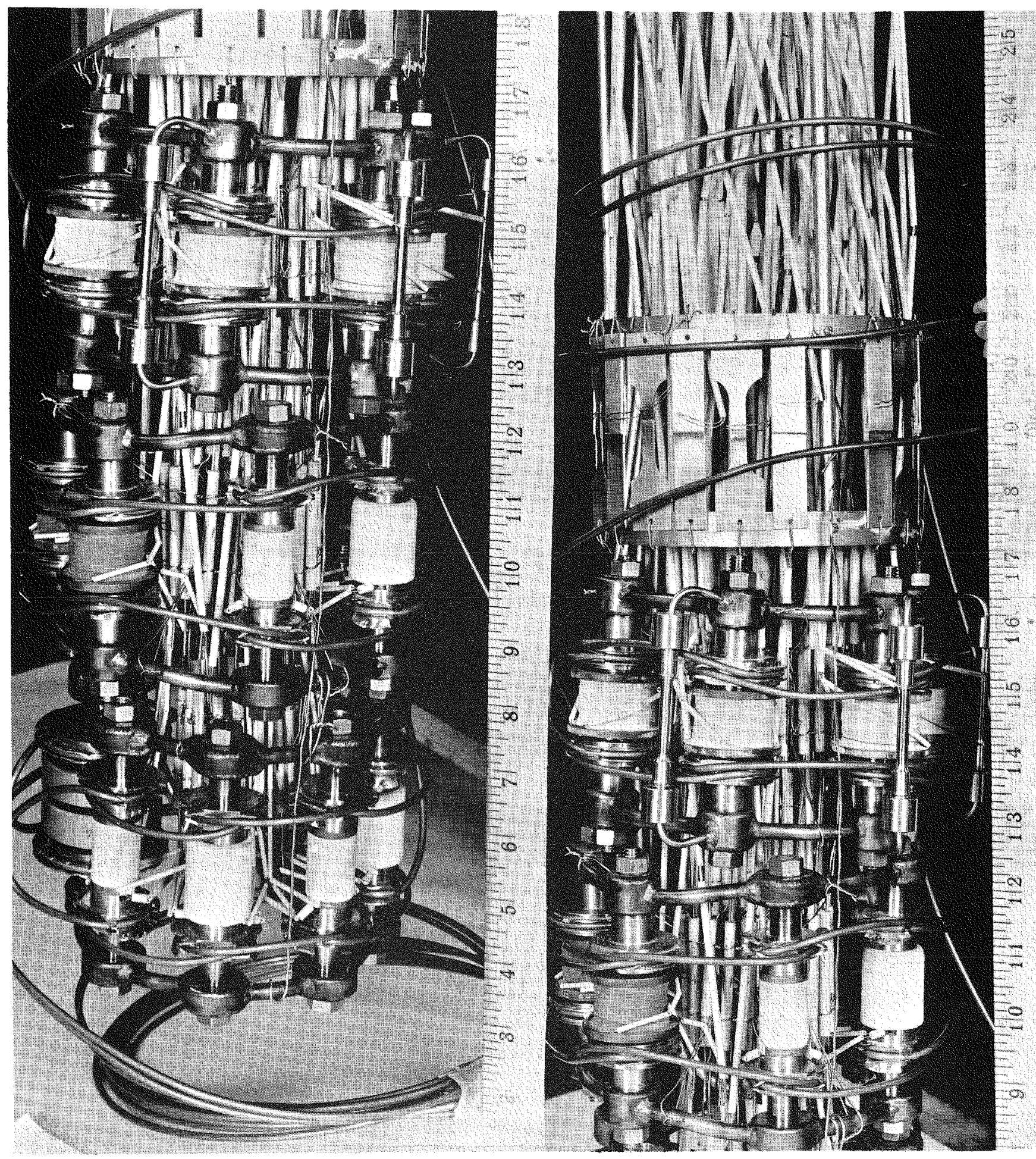

FIGURE 3. SPECIMEN ASSEMBLY FOR EXPERIMENT HIGH FLUX 1 
Figure 4 illustrates the heat-transfer design finally selected for the spool units. A similar configuration was used for the magnets. With the reference gamma heating rate of $0.2 \mathrm{w} / \mathrm{g}$, thermal radiation was inadequate and therefore a metallic rod was attached to each end of the specimen. The rods were coupled to a water circulation line to provide a conduction-heat-flow path to a heat sink. The water circuit was connected to an out-of-pile pumping and heat-exchange system. The cross section and length of the rod were utilized as the heat-transfer variables, being established by calculation and verified by analyses on a resistance-network analog.

Note that provision was made in this design for auxiliary heat input directly into the source-to-sink heat-conduction rods. One of the five auxiliary heaters employed in the experiment was thus coupled to each of the 14 spools in series fashion. Another heater was wound to serve the two magnet units similarly; in this case, care was taken to achieve noninductive windings. The other three heaters were coiled in a top-zone, middle-zone, bottom-zone orientation around the assembled unit.

In the case of the braze samples and the tensile samples, the heat-dissipation problem was less complex. The braze samples were amenable to gamma-heat dissipation by thermal radiation alone. The tensile bars required a small amount of watercoil cooling to augment thermal radiation.

\section{HF-2 Assembly}

A view of the HF-2 specimen assembly is shown in Figure 5. It included six Nichrome strips, $8 \mathrm{in}$. long by $3 / 16$ in. wide by 10 mils thick, coated on the central 6 -in. with various emittance coatings, primarily inorganic oxides. The purpose of the experiment was to determine the stability of the various coatings under irradiation. This was accomplished by measuring precisely the power required to maintain each strip at $600 \mathrm{~F}$, the temperature level of interest, and interpreting changes in this power level as indicative of changes in emittance characteristic. To implement this, care was taken in the design of the strips and the assembly to insure that radiation heat transfer would be virtually the only mode of heat dissipation from the strips.

The specimen strips were mounted on a framework and electronically isolated from it by porcelain insulators. Springs were used to maintain the specimen alignment by tensioning the strips through the various heating and cooling cycles during the experiment. Five thermocouples (5-mil-diameter elements) were attached to one face of each specimen and uniformly spaced vertically on the coated section. Power leads were attached to each end of the strips. These power leads were fed through single-pin, high-current-rating, glass-to-metal seals. This was the only departure from the 9-pin feedthroughs used for the thermocouple leads in this experiment and for all leads of the other three experiments.

To obtain a heat absorbing surface with a highly stable emittance characteristic, a special 6-in. -diameter containment chamber with the interior coated with flamesprayed $\mathrm{Cr}_{2} \mathrm{O}_{3}$ was employed. Ten thermocouples were attached to the inner wall of the chamber prior to the coating-application process to permit precise sink-temperature monitoring. 


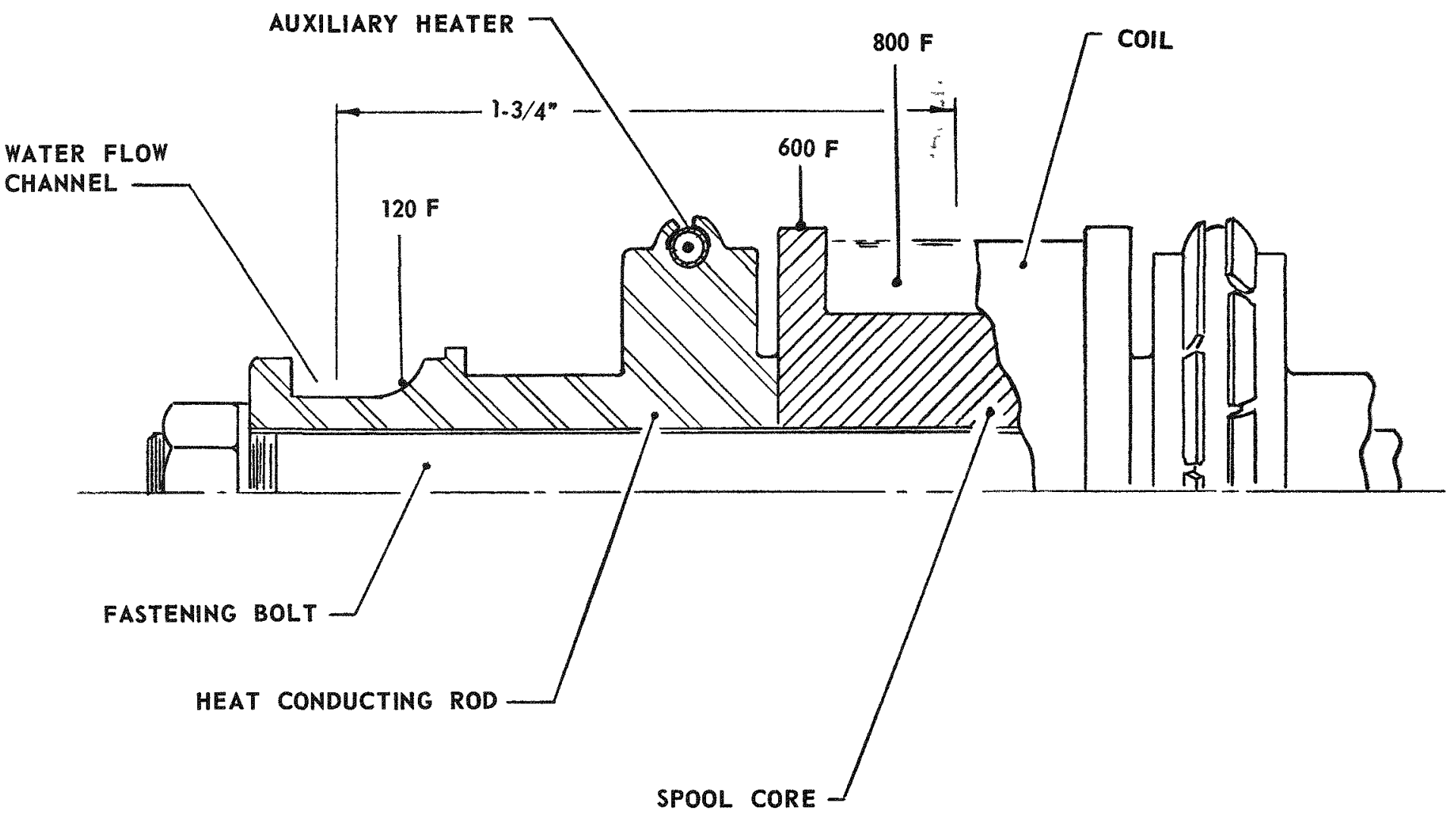

FIGURE 4. HEAT SINK FOR SPOOLS 


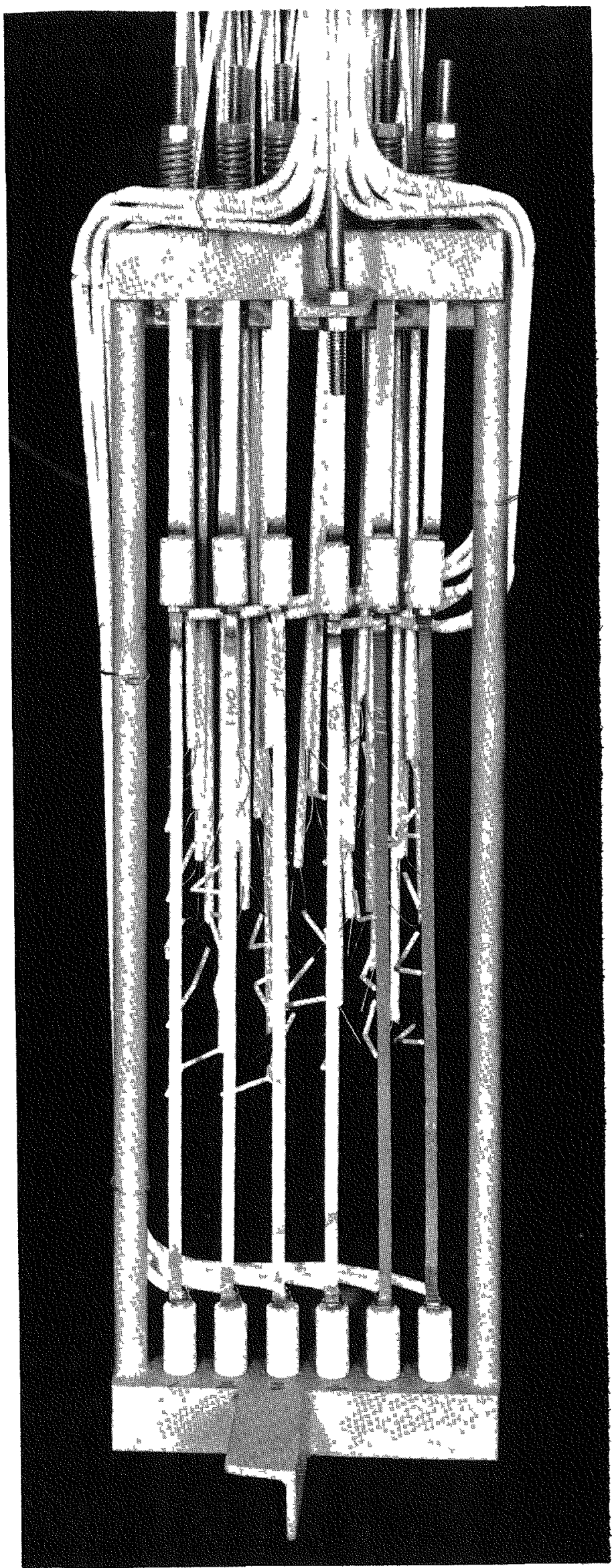

FIGURE 5. SPECIMEN ASSEMBLY FOR EXPERIMENT HIGH FLUX 2 
$\underline{H F-3 \text { Ass embly }}$

Figure 6 shows the HF-3 specimen assembly without the auxiliary heaters in place. The experiment included 48 specimens as follows:

15 tensile bars (titanium, molybdenum, Inconel, $\mathrm{H}-11$, and René 41)

17 friction samples (carbon, TiC, Mykroy, Micaceram, Stellite 6B, alumina, and a sample with an $\mathrm{Al}_{2} \mathrm{O}_{3}$ coating)

6 beryllium buttons coated with inorganic oxides (for evaluation of radiation-induced damage to emitting surfaces)

3 tensile braze samples similar to those in $\mathrm{HF}-1$

2 six-pin unmated connector halves

1 nineteen-pin mated connector

4 two-wire cable coils (glass-insulated, stainless steel-clad copper wire with stainless steel braid cover).

The HF-3 experiment had a specimen temperature specification of $1000 \mathrm{~F}$. Most of the specimens were of relatively low mass and, consequently, the heat-dissipation problem was considerably less severe than in the case of the HF-1 experiment. For example, it was not necessary to utilize relatively complex direct-conduction paths between individual specimens and a water-cooled sink. Rather, the specimens were mounted on, or suspended adjacent to, panels which formed a hexagonal enclosure (6-1/16 in. across flats and $14 \mathrm{in.}$ long). Thus, the means of specimen-to-panel heat flow by conduction and also by thermal radiation was provided. Heat dissipation from the panels to the reactor-water-contacting enclosures was by thermal radiation. The panels were 0.050-in. -thick nickel plates with grit-blasted surfaces which yielded a high effective emissivity.

The only specimens which appeared to have a marginal gamma-heat dissipation capability with this heat-transfer scheme were the Stellite $6 \mathrm{~B}$ friction samples and the large mated connector. As a precaution, these particular samples were located so that they could "view" directly the water-contacting containment wall. This was accomplished by providing appropriately located openings in the mounting panels. In addition, the mated connector was located in the minimum gamma-heat zone of the specimen array.

Three independently controlled sheathed auxiliary heaters were incorporated into the system in the space between the hexagonal enclosure and the cold wall. Each heater was shaped into an up-and-down configuration so that it would cover the projected area of two of the six panels that formed the hexagonal structure.

HF-4 Assembly

Figure 7 shows the HF-4 specimen assembly without the auxiliary heating coils in place. The experiment included 32 specimens as follows: 


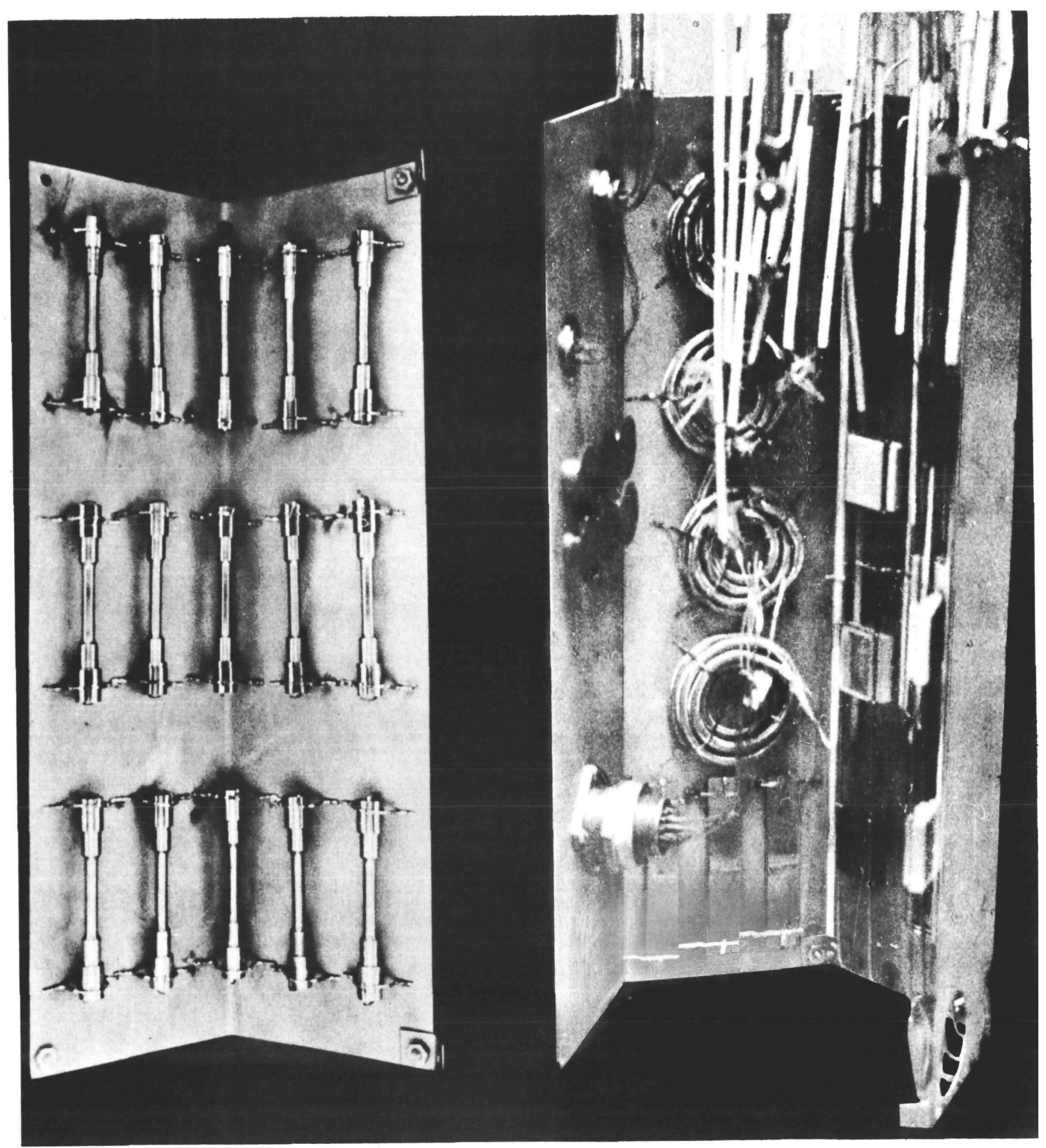

FIGURE 6. SPECIMEN ASSEMBLY FOR EXPERIMENT HIGH FLUX 3 


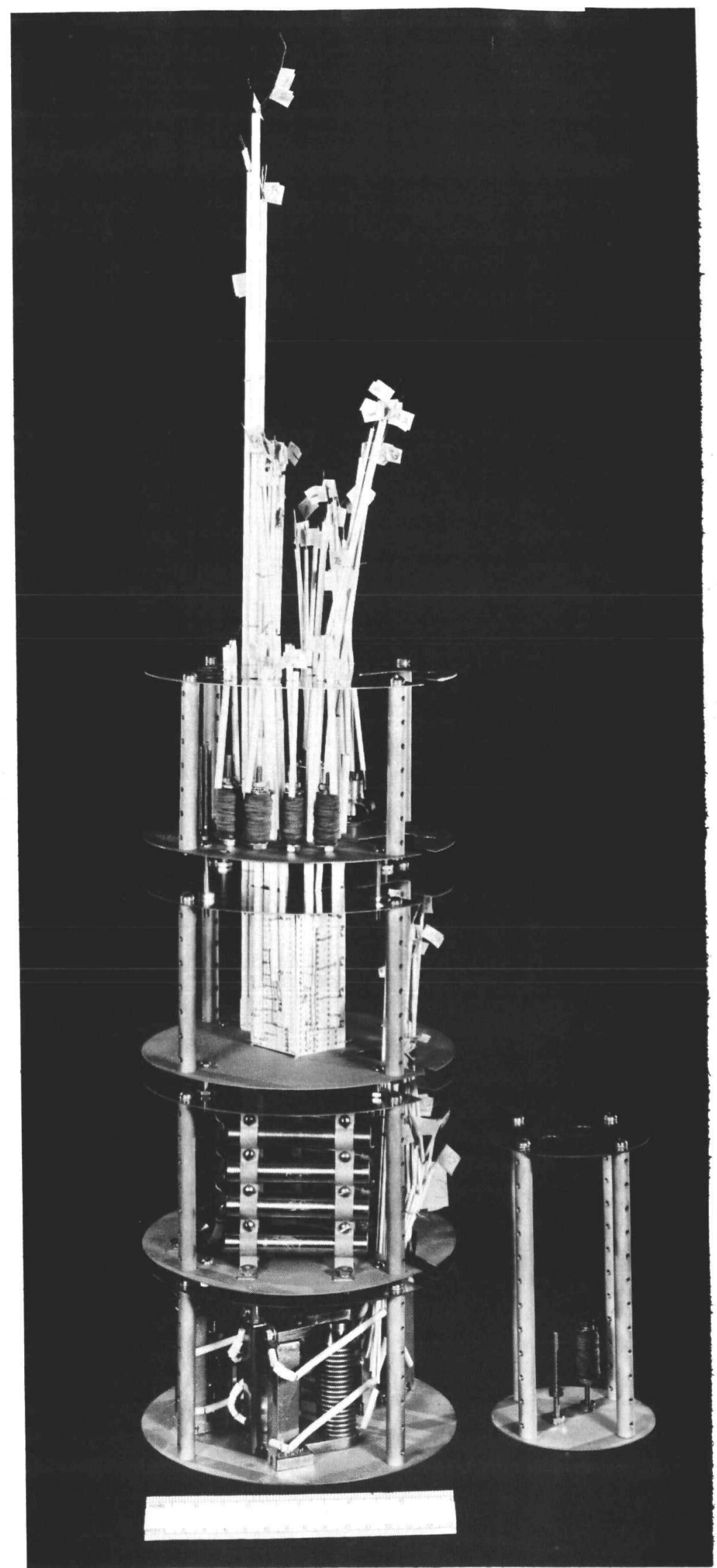

FIGURE 7. SPECIMEN ASSEMBLY FOR EXPERIMENT HIGH FLUX 4 
1 platinum resistance temperature sensor

10 spools of a much smaller size than in HF-1, each spool having copper-wire coils insulated with a high-temperature material; core of ceramic-material

12 samples of various materials (Kentanium, titanium, Stellite 6B and carbon-base materials) to assess dimensional stability characteristics

3 spring-loaded stainless steel fixtures holding approximately 40 specimens in intimate contact for self-welding behavior determinations and spring characteristics

2 six-pin high-temperature connector halves

4 TIMM circuits (containing resistors, capacitors, diodes, and triodes).

The target temperature levels for the specimens were $800 \mathrm{~F}$ for the spools and connectors, $1000 \mathrm{~F}$ for the temperature sensor, self-welding fixtures, and dimension stability samples, and 1087 F for the TIMM circuits. While, as in HF-3, the specimens were not especially massive, the multitemperature specification dictated an as sembly configuration in which specimen groups would be compartmented, be thermally isolated from each other, and have independent temperature control. An additional requirement was the placing of two of the spool specimens in a low neutron (and gamma) flux region, still maintaining the $800 \mathrm{~F}$ temperature level.

As a result of these considerations, the hexagonal-structure configuration used in Experiment $\mathrm{HF}-3$ was not applicable for $\mathrm{HF}-4$. Rather, a zonal array along the containment-chamber axis was selected with the specimens in each zone surrounded by a separate coiled heater for individual temperature control. Five such zones were formed by 0.037 -in. - thick nickel disks supported horizontally by spacer posts. The zones were thermally isolated by a gap between adjacent ones and also by a certain degree of radiation heat-transfer control. The latter was accomplished by grit blasting the inside (specimen facing) surfaces of the disks, as well as the surfaces of the spacer rods, to obtain a high emissivity and thus encourage thermal-radiation interactions within the zone. Conversely, the outside (adjacent zone facing) surfaces were buffed to reduce emissivity and thus minimize zone-to-zone heat exchange.

The uppermost zone which housed the two low-flux spool specimens was located well above the other four in which the remaining specimens were mounted. Except for the temperature sensor and the TIMM components, the specimens were clamped or bolted to the disk members. The TIMM components were attached to four alumina sheets which were mounted in a box array in the center of one of the specimen subassembly zones. The temperature sensor assembly was suspended in an open region of the lower zone. The sensor end was not in contact with the structure or the disk members. Cutouts were provided in the various zone-forming disks for leads and for the temperature sensor. 
Background

The factors which dictated the nuclear environment for the four experiments described in this report were as follows:

(1) The use of the BRR facility shown in Figure 8. This facility has the highest available flux level at this reactor, exclusive of the two experiment facilities within the core. The latter could not be used since they are not large enough to accommodate the large test chamber required to house the multispecimen arrays that were involved.

(2) A time period of not more than three reactor cycles (14 days per cycle with the reactor at full power for 12 days) per experiment. This criterion was based on the time available to perform the four experiments and subsequent ones in the Atomics Internationalprogram series.

(3) A specification by Atomics International personnel that the neutron and gamma fluxes received by the specimens adhere as closely as possible to the spectra listed in Tables 1 and 2 .

In addition to the criteria regarding spectra, Atomics International personnel included the following as an original specification:

(1) The specimens are to receive an integrated fast-neutron exposure (greater than $0.1 \mathrm{Mev}$ ) of $2.9 \times 1019 \mathrm{n} / \mathrm{cm}^{2}$

(2) The corresponding total gamma exposure is to be $3.7 \times 10^{10} \mathrm{R}$.

These levels represented estimates of conditions desired to simulate prototype operation, derived from the information then available.

It was very quickly obvious from the mock-up data that a 36-day in-pile period would provide a radiation exposure in which (1) the total fast flux would fall short of $2.9 \times 10^{19} \mathrm{n} / \mathrm{cm}^{2}$ and (2) the total gamma would exceed $3.7 \times 10^{10} \mathrm{R}$. Since there was no way of altering the flux-to-gamma ratio without appreciably lengthening the exposure time, the experiments were carried out without any attempt at such alteration. As it turned out, the departure on the low side from the $2.9 \times 10^{19} \mathrm{n} / \mathrm{cm}^{2}$ was even greater in each individual experiment than expected on the basis of the mock-up data.

\section{Measurements Techniques}

The investigation of flux levels included (1) mock-up experiments to provide information relative to the spectral distribution and spectral characteristics of the neutron flux and gamma exposure rates over the volume of the test-specimen assemblies 


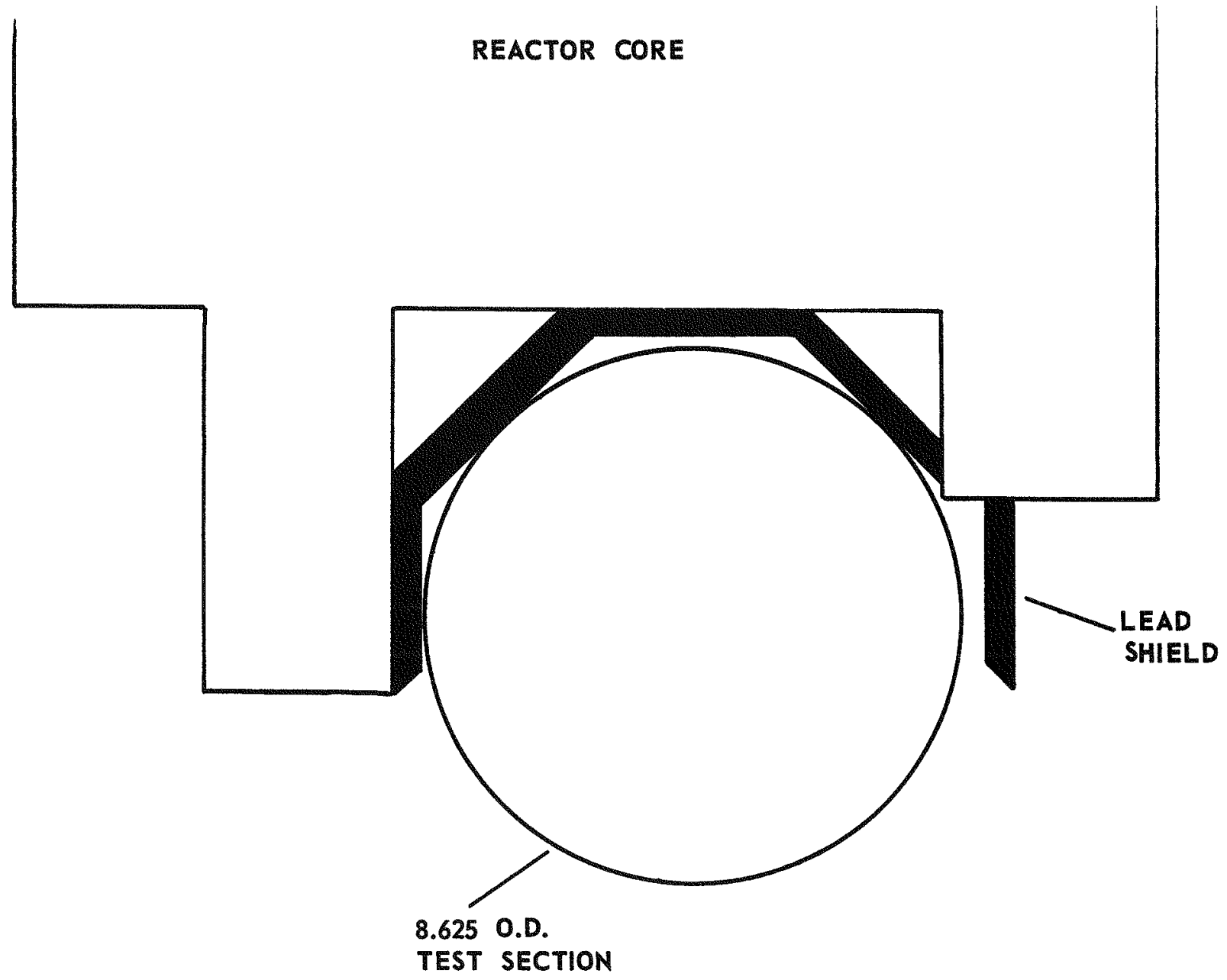

FIGURE 8. TEST SECTION CORE LOCATION 
and (2) the procurement of detailed information about the radiation exposures actually received by the test specimens. The latter was accomplished by dosimetry of one or more types dispersed throughout the specimen arrays and correlation of the data thus obtained with those obtained from the mock-up runs.

The mock-up facility was fabricated by a section of 8-in.-diameter Schedule 40 aluminum pipe $40 \mathrm{in}$. long. The bottom was sealed with $1 / 4 \mathrm{in}$. plate and the top was fitted with a removable cap and special lead-out tube for inserting dosimeters which were held within the chamber by special holders. The mock-up runs were conducted at reactor power levels ranging from a few kilowatts to $200 \mathrm{kw}$ depending on the activation characteristics of the detectors employed. Extrapolation to the full reactor power of $2 \mathrm{Mw}$ was made using information gathered from a power monitor that is capable of monitoring the reactor power down to $1 \mathrm{kw}$. **

The mock-up plus irradiation-experience dosimetry provided a basic analysis of the incident neutron field by division into the following three energy groups:

(1) Fast neutron flux - neutrons with energies greater than $0.1 \mathrm{Mev}$. To measure integrated fluxes and obtain a representation of the spectrum in this range, a set of detectors with cross sections approximately describing a step increase in value at different threshold energies from a few tenths of a Mev to several Mev was used.

(2) Resonance neutron flux - neutrons with energies from about $0.4 \mathrm{ev}$ to about $0.1 \mathrm{Mev}$. The cadmium-difference method is used to measure the differential neutron flux in the resonance-neutron-energy region. This method assumes that the differential neutron flux between energy $E$ and $E+d E$ is expressed by

$$
\phi(E) \mathrm{dE}=\frac{\phi_{\mathrm{O}}}{\mathrm{E}} \mathrm{dE},
$$

where $\phi_{0}$ (called the spectral function parameter) is given ${ }^{* * *}$ by

$$
\phi_{0}=\frac{2.27 \phi_{\text {th }}}{(\mathrm{CR}-1)(1+\alpha)},
$$

where

$$
\begin{aligned}
\phi_{\mathrm{th}}= & \text { thermal neutron flux } \\
\mathrm{CR}= & \text { cadmium ratio } \\
\alpha= & \text { a number characteristic of the resonance cross section } \\
& \text { of the detector. }
\end{aligned}
$$

The factor 2.27 includes the effect of the cadmium-cover thickness.

\footnotetext{
*plummer, A. M. . "Nitrogen-17 Decay Monitors Reactor Power", Nucleonics, 22 (4), 84 (A pril, 1964).

" Tentative Recommended Practice for Measuring Neutron Flux Environment for Reactor Irradiated Specimens", ASTM E 199-62T.
} 
This method is valid only if the neutron flux has a $1 / E$ energy distribution. The validity of this assumption was established in the mock-up by calculating $\phi_{\mathrm{o}}$ from the measured cadmium ratio of a number of resonance detectors.

(3) Thermal neutron flux - neutrons with energies less than about 0.4 ev. These measurements are made by exposing identical radioactivants with and without a 20 to 40 -mil thick cadmium cover. The difference in response is proportional to thermalneutron flux.

Gamma exposure rates were measured in the mock-up with $10 \mathrm{cc}$ graphite-walled ionization chambers. A small flow of carbon dioxide at atmospheric pressure is maintained through each chamber. High voltage is supplied by a regulated power supply. The chambers are operated at an applied voltage of 500 volts and current outputs are measured with a Keithley Model 414 micromicroammeter.

Prior to the measurements, the chambers are calibrated against copper-modified ferrous sulfate chemical dosimeters at the Battelle Cobalt-60 Irradiation Laboratory. In-pile exposure-rate measurements are corrected for the presence of fast neutrons. The correction is approximately $9.3 \times 10^{-5} \mathrm{erg} /(\mathrm{g})(\mathrm{hr})($ carbon $)$ per $\mathrm{n} /\left(\mathrm{cm}^{2}\right)(\mathrm{sec})$.

The gamma spectrum was measured in the energy range of $0.37 \mathrm{Mev}$ to $8.0 \mathrm{MeV}$ with a three-crystal Compton-pair spectrometer. The spectrometer noise level limited the gamma measurements to energies above $0.37 \mathrm{Mev}$. However, in the irradiation experiments, the percentage of total gamma below this energy was probably quite small because of the use of a lead shield around the test facility. The high-energy measurements were limited by the instrument sensitivity and the low percentage of gammas with energies greater than $8.0 \mathrm{Mev}$.

The integrated fast-neutron fluxes for individual specimens in the irradiation-test assemblies were measured with iron or nickel dosimeter wires which were dispersed throughout the test packages. Measured threshold flux values determined from these dosimeters were corrected to integral fast flux greater than $0.1 \mathrm{Mev}$ and $0.5 \mathrm{Mev}$ by the fast-neutron spectrums measured in the mock-up dosimetry. Cobalt-aluminum wires $(0.75 \mathrm{w} / 0$ cobalt) were used to measure the integrated thermal-neutron fluxes for the test irradiations. Integrated resonance fluxes were calculated from the integrated fast fluxes by using the ratios of resonance flux to fast flux that were measured in the mock-up. Gamma exposures were calculated from measured gamma-exposure rates in the mock-up and specimen exposure times.

The exposures determined in this manner for the components in each experiment are given in the Appendix. Included are four-group neutron exposures and gamma exposures. 


\section{Mock-up Data}

\section{Neutron Spectra}

The fast-neutron spectrum was measured with the reactions $\mathrm{Pu}^{239}(\mathrm{n}, \mathrm{f}), \mathrm{U}^{238}$ $(n, f), N^{58}(n, p), S^{32}(n, p), F e^{54}(n, p)$, and $A^{27}(n, \alpha)$ at two points on the axis of the mock-up at positions 5 and 12 in. from the bottom of the test region. The results of these measurements normalized to $2 \mathrm{Mw}$ reactor operation are shown in Figure 9 . The data points were fitted to the integral Watts fission spectrum:

$$
\int_{E}^{\infty} e^{-E} \sinh \sqrt{2 E} d E .
$$

Plutonium measures the integral neutron flux above $4 \mathrm{kev}$. The plutonium datum point plotted in Figure 9 represents the integral neutron flux greater than $4 \mathrm{kev}$. In order to obtain an approximation of the integral neutron flux above $100 \mathrm{kev}$, the integral neutron flux between $4 \mathrm{kev}$ and $100 \mathrm{kev}$ was subtracted from the plutonium flux. This correction was based on the resonance neutron measurements at the same location in the mock-up. The plutonium flux corrected up to $100 \mathrm{kev}$ agreed quite well with the Watts fissionspectrum value that was extrapolated down to $100 \mathrm{kev}$ on the basis of the higher energy threshold detector information. Succeeding fast-neutron-flux measurements in the mock-up and in-pile experiments were interpreted on the basis of an integral Watts fission-spectrum representation of the fast-neutron spectrum.

The resonance neutron spectrum was measured with the reactions $\mathrm{Co}^{59}(\mathrm{n}, \gamma)$, $\mathrm{Cu}^{63}(\mathrm{n}, \gamma), \mathrm{V}^{51}(\mathrm{n}, \gamma)$, and $\mathrm{Al}^{27}(\mathrm{n}, \gamma)$ along the axis of the mock-up at a position 12 in. from the bottom of the test region. The results of these measurements normalized to $2 \mathrm{Mw}$ reactor operation are shown in Figure 10. Validity of the assumption that the resonance energy spectrum is proportional to the reciprocal neutron energy was confirmed over the measured energy interval. The mean value of the spectral function parameter $\left(\phi_{0}\right)$ for the four detectors was $7.42 \times 10^{11} \mathrm{n} /\left(\mathrm{cm}^{2}\right)(\mathrm{sec})$ with a maximum deviation of less than \pm 4 per cent.

Measurement of the thermal neutron flux along the axis of the mock-up $12 \mathrm{in}$. from the bottom of the test region with bare and cadmium-covered cobalt foils gave a value of $3.37 \times 10^{11} \mathrm{n} /\left(\mathrm{cm}^{2}\right)(\mathrm{sec})$. The measurements were made with a $0.010-\mathrm{in}_{0}$ thick cadmium sleeve placed around the mock-up chamber.

Table 1 presents a comparison of the measured neutron spectrum along the axis of the mock-up $12 \mathrm{in.}$ from the bottom of the test region with the spectrum specified at Atomics International. Both are normalized to an integrated neutron flux of $1.0 \times 1019$ $\mathrm{n} / \mathrm{cm}^{2}$ in the energy range of 0.5 to $18 \mathrm{Mev}$. As indicated, the measured neutron flux from 0.017 to $0.1 \mathrm{Mev}$ was a factor of approximately 3 higher than the specified level and the measured thermal neutron flux was a factor of approximately 3 lower than the specified level. Since the test section was located immediately in front of the reactor core face, reduction of the resonance flux to better approximate the specified level was not practical. Because of the small importance of the thermal neutrons in comparison to the higher-energy neutrons as a radiation-damage mechanism to materials, further modification of the thermal-neutron flux was not required. 


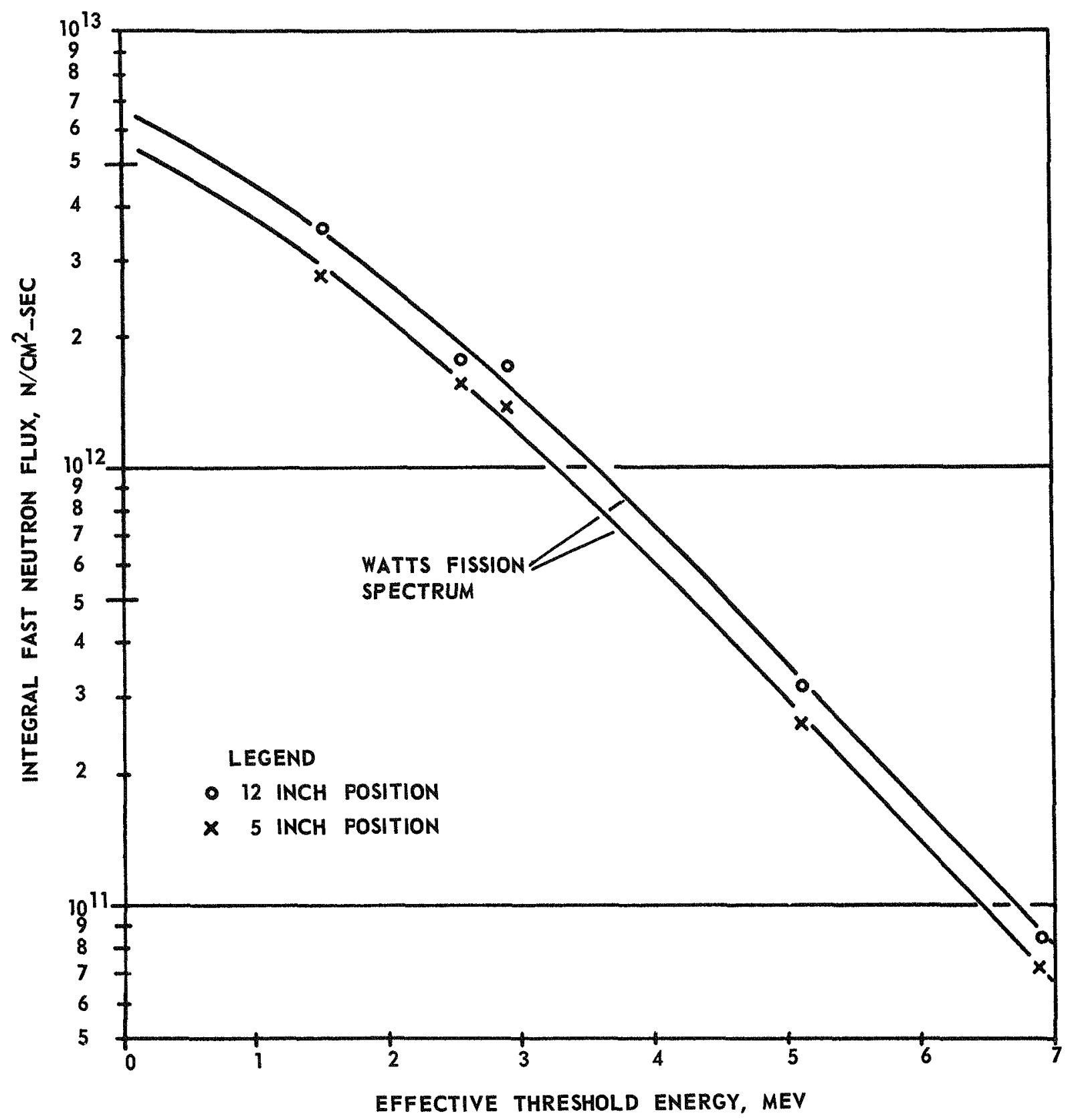

FIGURE 9. FAST NEUTRON SPECTRUM 


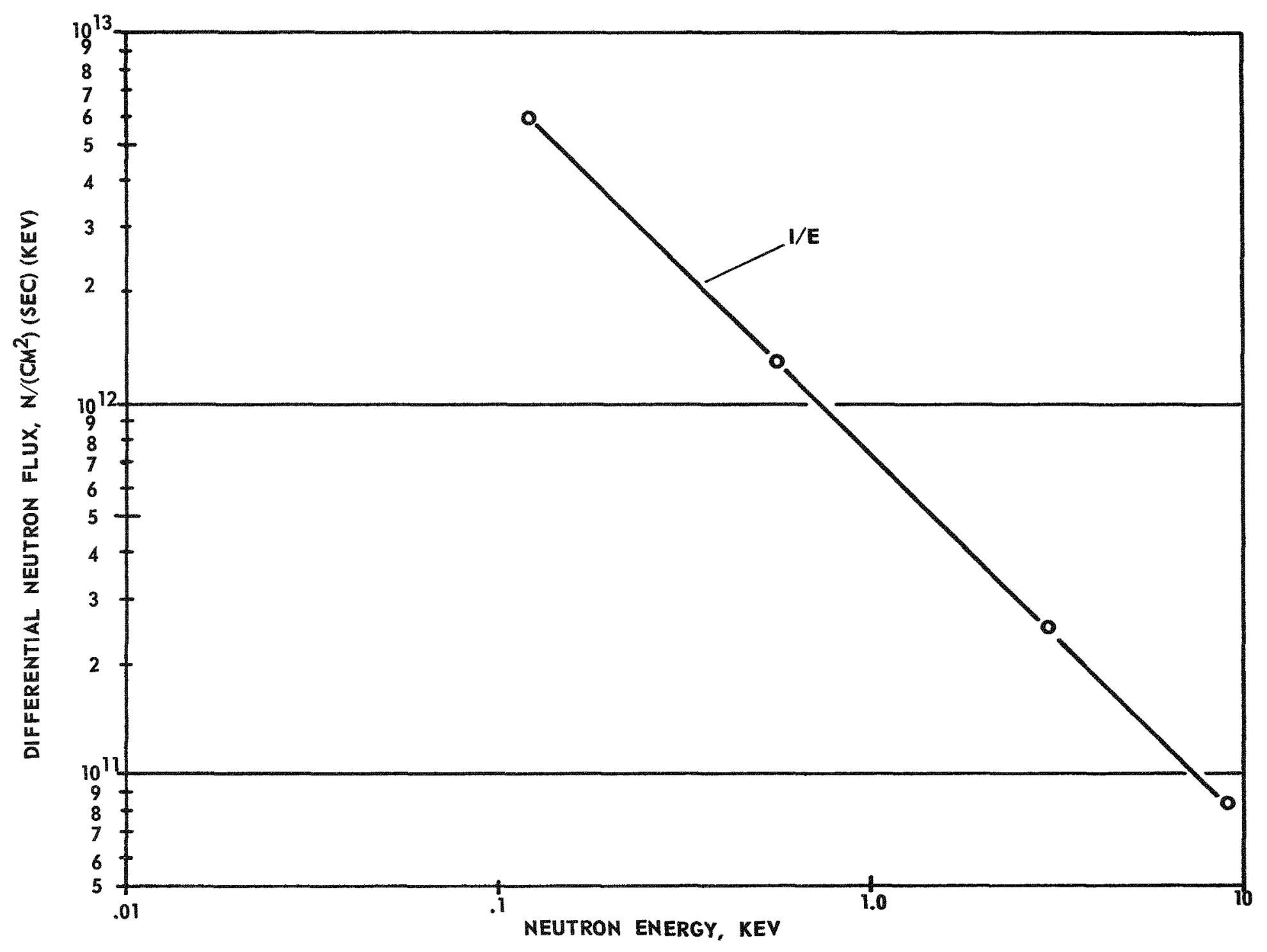

FIGURE 10. RESONANCE NEUTRON FLUX SPECTRUM 
TABLE 1. COMPARISON OF NEUTRON SPECTRA

NORMALIZED TO AN INTEGRATED

FAST FLUX OF $1.0 \times 10^{19} \mathrm{~N} / \mathrm{CM}^{2}$

(0.5-18 MEV)

\begin{tabular}{lcc}
\hline $\begin{array}{c}\text { Neutron } \\
\text { Energy } \\
\text { Range }\end{array}$ & $\begin{array}{c}\text { Measured } \\
\text { in Mock-Up } \\
\text { Facility }\end{array}$ & $\begin{array}{c}\text { Specified by } \\
\text { Atomics } \\
\text { International }\end{array}$ \\
\hline$<0.4 \mathrm{ev}$ & $0.6 \times 10^{18}$ & $1.5 \times 10^{18}$ \\
$0.017-0.1 \mathrm{Mev}$ & $2.3 \times 10^{18}$ & $0.8 \times 10^{18}$ \\
$0.1-0.5 \mathrm{Mev}$ & $1.5 \times 10^{18}$ & $2.1 \times 10^{18}$ \\
$0.5-18 \mathrm{Mev}$ & $1.0 \times 10^{19}$ & $1.0 \times 10^{19}$ \\
\hline
\end{tabular}

\section{Neutron Flux Distributions}

The fast-neutron flux distribution was measured along the axis of the mock-up and at four radial positions over a 16-in. axial length with nickel-wire dosimeters. The maximum axial change in the neutron flux greater than $0.1 \mathrm{Mev}$ was approximately 2.5 and the maximum radial variation was approximately 2.0 .

The resonance neutron flux was measured over a 16 -inch axial length at the same radial positions as the fast-neutron-flux measurements. Maximum axial and radial changes in the resonance flux were approximately 1. 5.

Thermal-neutron flux measurements were made at the same radial positions as the resonance and fast flux measurements over a 20 -in. axial length. The maximum flux variations were 1.4 in the radial direction and 2.5 in the axial direction. The axial distribution in the flux values were considerably different from the resonance and fast flux distributions because of thermal-neutron streaming through a hole in the bottom of the cadmium shield.

Figure 11 indicates the results of these measurements along the mock-up axis.

$\underline{\text { Gamma }}$

Figure 12 indicates the gamma-exposure rate* distribution along the axis of the mock-up normalized to $2 \mathrm{Mw}$ reactor power. The top curve presents the distribution measured prior to the start of the in-pile experiments. During the first experiment $(\mathrm{HF}-1)$, it became necessary to reduce the gamma heating in the specimen array by inserting a lead shield between the reactor core and the test chamber. The bottom curve in Figure 11 indicates the distribution measured subsequently with this shield in place.

*Gamma-exposure rates are reported in units of $R / \mathrm{hr}$. This unit was obtained from the measured unit of ergs/(g)(hr)(carbon) by use of the conversion factor of $87.7 \mathrm{ergs} / \mathrm{g}$ (carbon) $/ \mathrm{R}$. 


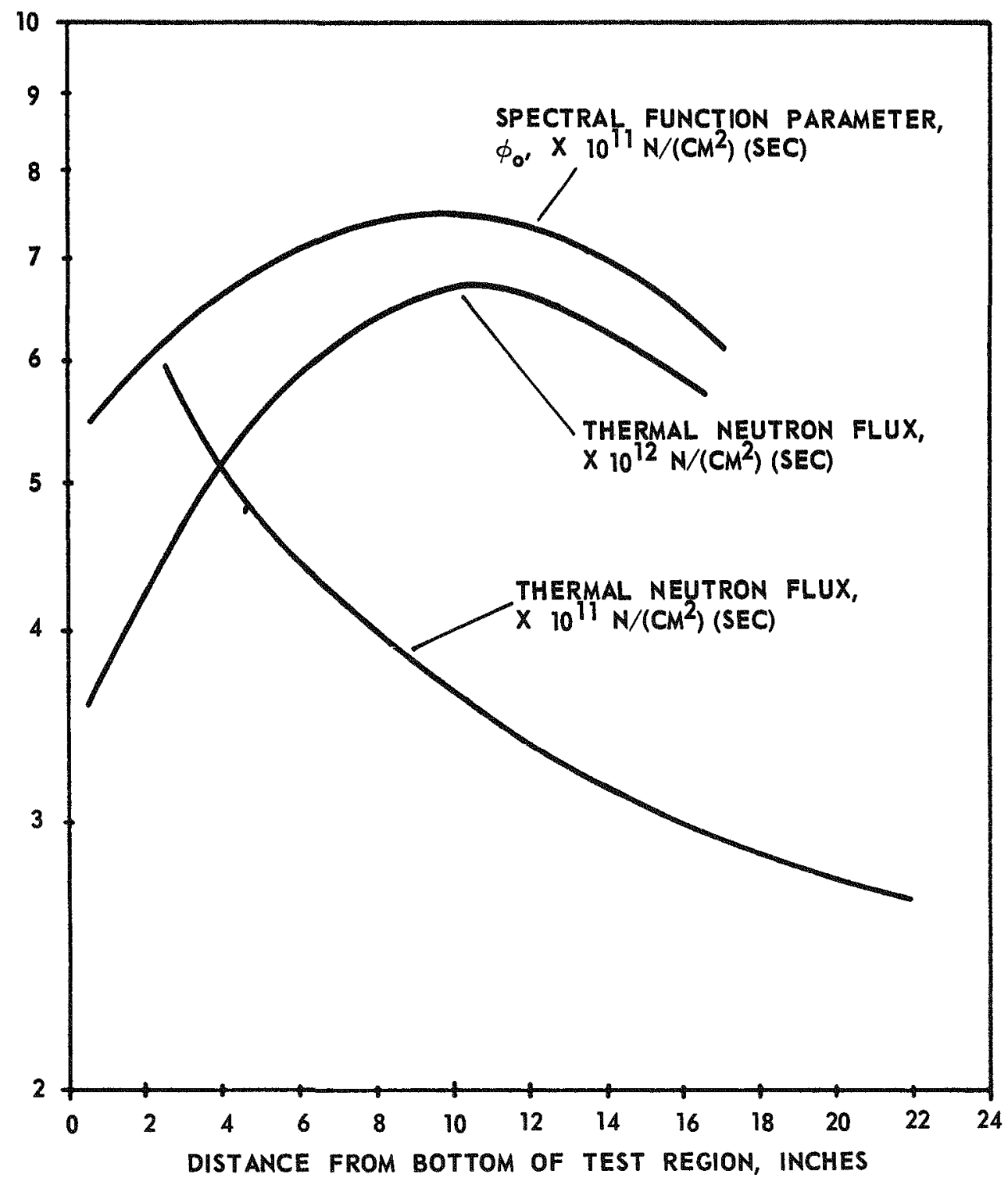

FIGURE 11. NEUTRON FLUX DISTRIBUTIONS IN MOCKUP 


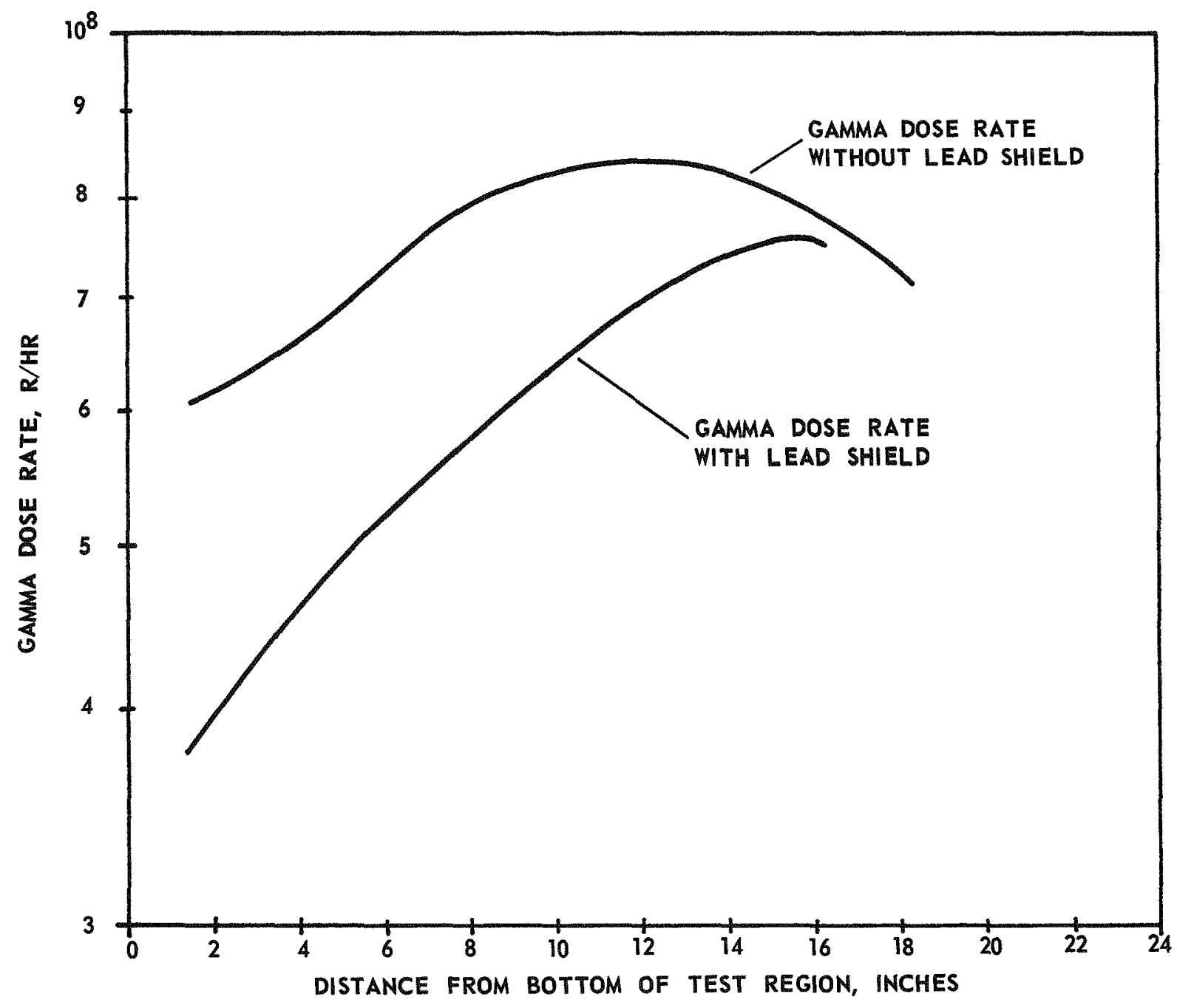

FIGURE 12. GAMMA DOSE RATE IN MOCKUP 
The maximum axial and radial changes in the gamma-exposure rate were about 1.4 and 1.3, respectively, before addition of the shield and 2.0 and 1.6 , respectively, after its addition.

A comparison of the measured gamma spectrum with that specified by Atomics International is given in Table 2. Both spectra are normalized to a total exposure of $5 \times 10^{10} \mathrm{R}$.

TABLE 2. COMPARISON OF GAMMA SPECTRA NORMALIZED TO A TOTAL EXPOSURE OF $5 \times 10^{10} \mathrm{R}$

\begin{tabular}{lcc}
\hline $\begin{array}{c}\text { Energy } \\
\text { Range, } \\
\text { Mev }\end{array}$ & $\begin{array}{c}\text { Measured in } \\
\text { Mock-up } \\
\text { Facility, } \\
109 \mathrm{R}\end{array}$ & $\begin{array}{c}\text { Specified by } \\
\text { Atomics } \\
\text { International, } \\
19^{9} \mathrm{R}\end{array}$ \\
\hline $0-0.375$ & -- & 4.2 \\
$0.375-0.625$ & 4.2 & 6.1 \\
$0.625-0.875$ & 6.5 & 5.3 \\
$0.875-1.25$ & 10.6 & 7.6 \\
$1.25-1.75$ & 10.8 & 8.8 \\
$1.75-2.25$ & 7.7 & 7.0 \\
$2.25-3.0$ & 5.5 & 5.7 \\
$3-4$ & 2.7 & 3.2 \\
$4-5$ & 1.1 & 1.2 \\
$5-6$ & 0.4 & 0.3 \\
$6-7$ & 0.3 & 0.3 \\
$7-8$ & 0.3 & 0.2 \\
$8-9$ & -- & 0.5 \\
$9-10$ & -- & 0.1 \\
\hline
\end{tabular}

\section{IN-PILE OPERATION}

The following summarizes, very briefly, noteworthy operational data for the individual experiments.

\section{Experiment HF-1}

\section{Operation}

The HF-1 experiment was irradiated at the Battelle Research Reactor during Cycles 113, 114, and 116: the total exposure period was 839 hours. Leading events during the progress of the experiment are noted below: 
(1) At the start, temperature levels in the 600 to $800 \mathrm{~F}$ range were obtained with the reactor operating at approximately 65 per cent of full power. It was apparent from this that a reduction in gammaheating level was required, and, subsequently, a temporary shield fabricated of aluminum-covered 3/8-inch-thick lead strip was inserted between the test section and the reactor core to reduce the gamma-heating rate, particularly in the spool - and magnet-location zone. During the remainder of the first cycle and during the second cycle, the operation was fairly routine.

(2) During the subsequent cycle (BRR Cycle 115), the experiment was not operated in-pile inasmuch as a new reactor core was installed and a limited amount of re-evaluation dosimetry was desired. Also, gamma dosimetry was performed with the lead shield in place.

During this period, the vacuum chamber was checked for leaks. This revealed that the Butyl rubber O-rings which formed the seal between the test section chamber and the vacuum line had degraded severely as a result of the radiation exposure. Apparently, the streaming path through the 8-in. diameter vessel caused the $O-r i n g s$ to receive a damaging radiation dose even though they were located several feet from the top of the reactor core. Neoprene rubber O-rings were substituted for the Butyl rubber members and natural rubber O-rings were ordered for future experiments on the basis of radiation-damage criteria gleaned from the literature.

(3) The final cycle of operation proceeded routinely.

(4) At the end of the experiment, 30 of the original 34 thermocouples appeared to be operating satisfactorily.

Temperature Levels

Table 3 presents time-averaged temperature levels for the different types of specimens included in the irradiation. In the case of the spools, readings from thermocouples located on exposed surfaces were used for reference purposes only. The coil temperatures in-pile were assessed by measuring coll resistances and utilizing a relation between these resistances and temperature established from out-of-pile experiments. The use of this relation assumed no change in coil resistance with radiation dosage. The measurements showed that coil-resistance-indicated temperatures were about $200 \mathrm{~F}$ higher than the corresponding spool-surface temperatures determined directly by thermocouples.

As indicated in Table 3, it was not possible to eliminate a considerable temperature spread by the auxiliary-heat regulation available. When this became apparent early in the irradiation, it was decided to hold the spool temperatures (as indicated by the coil-resistance measurements) as closely as possible to the $800 \mathrm{~F}$ level, inasmuch as their temperature could be effectively regulated by the heater integral with their conduction heat-transfer rods. 
TABLE 3. TIME-AVERAGED TEMPERATURE LEVELS FOR HF-1 EXPERIMENT

\begin{tabular}{lccc}
\hline \hline \multirow{2}{*}{ Specimen Type } & \multicolumn{3}{c}{ Temperature, F } \\
\cline { 2 - 4 } Spools (large geometry) & $700-840$ & Cycle 114 & Cycle 116 \\
Spools (small geometry) & $750-870$ & $750-850$ & $750-850$ \\
Braze samples & 800 & $740-870$ & $650-800$ \\
Tensile specimens & 900 & 850 & 850 \\
Magnets(a) & 800 & 950 & 875 \\
& & 800 & 775 \\
\hline
\end{tabular}

(a) The thermocouple attached to one magnet consistently read above $200 \mathrm{~F}$ higher than that attached to the other. The higher reading was believed to be faulty since it was inconsistent with other temperatures in the system.

\section{Vacuum Levels}

The following describes briefly the vacuum-level conditions achieved for the $H F-1$ experiment:

(1) Without a specimen subassembly, vacuum levels of 7 to $8 \times 10^{-6}$ torr were achieved in the containment system after pumping times of 16 to 18 hours.

(2) After installation of the experimental array and prior to heating, the vacuum level was $1.5 \times 10^{-5}$ after 16 to 18 hours of pumping time. During back-pool operation of the specimens at temperatures up to $800 \mathrm{~F}$, the vacuum level gradually improved, reaching 6 to $9 \times 10^{-6}$ torr near the end of these runs.

(3) In general, the vacuum level of the system was $10^{-5}$ tor $r$ or less during the in-pile operation. There were brief periods of exception to this. The foremost of these occurred near the end of the second irradiation cycle when the O-ring closures were probably damaged to the point of allowing some leakage. Other short out-of-vacuum-specification operating periods took place owing to a diffusion-pump-heater failure and to assorted liquid-nitrogen-level control problems associated with the vacuum-system cold trap.

\section{Electrical Measurements}

Measurements were made as the HF-1 experiment progressed to determine (1) the insulation resistance between each of the pair of coils and the core on which they were wound, (2) the insulation resistance between the two coils on each individual spool, and (3) the resistance of each coil to indicate possible shorted turns. Measurements were made continuously during the start up period, and at 8-hour intervals for the remainder of the irradiation.

The insulation resistance measurements were made with a General Radio Type 544 Megohm Bridge, with an applied potential of $90 \mathrm{v}$. Insulation resistances below 0.1 megohms were measured with a five-dial Wheatstone Bridge. The coil resistances were 
measured with a Kelvin Bridge, with a four-wire circuit attached to the two specimen leads just above the containment chamber header. In this manner, the leads between the header and the instrumentation did not enter into the measurement. Measurements were also made of the resistance of shorted pairs of dummy leads between the header and the specimen zone to provide a means of correcting for this lead resistance.

\section{Experiment HF-2}

\section{Operation}

The HF-2 experiment was irradiated for a total of 280 hours during BRR Cycle 117. The operation was uneventful.

\section{Temperature Levels}

Except during power-monitoring procedures, the specimen temperatures were maintained at $600 \pm 5 \mathrm{~F}$ during the entire exposure. The temperatures of the inner wall of the test section were monitored during the experiment and found to range from $107 \mathrm{~F}$ to $122 \mathrm{~F}$.

\section{Vacuum Levels}

The vacuum level measured near the test section ranged from about $1 \times 10^{-5}$ tor $r$ down to about $3 \times 10^{-6}$ torr near the end of the one-cycle irradiation. This low vacuum level could be attained inasmuch as the net surface area of the specimen assembly was relatively low. Apparently, the outgassing rate of the $\mathrm{Cr}_{2} \mathrm{O}_{3}$ coating on the interior wall of the containment chamber was not significant.

\section{Electrical Measurements}

Power-input measurements to the individual strips were made twice daily during the irradiation using the following procedure:

(1) Turn off all heater power

(2) Equilibrate at temperature (gamma heating only)

(3) Raise Specimen 1 to $600 \mathrm{~F}$ and measure temperatures, current, and voltage

(4) Turn off power

(5) Repeat Steps 3 and 4 for each of the other five specimens

(6) Return all specimens to $600 \mathrm{~F}$. 
During measurements of the electrical power required to maintain the strips at temperature, the temperature of the strips was maintained at $600 \pm 1 \mathrm{~F}$. Temperature measurements were made with an $L$ \& $N$ type K-3 potentiometer using a distilled-water ice bath for the cold junction. The power supplied to each strip was measured by measuring the voltage drop between the thermocouples and the current through the strip. The voltage drop between the thermocouples was measured to $0.2 \mathrm{v}, \pm 0.3$ per cent, with a Fluke Model 803 differential voltmeter. The current was determined by measuring the voltage drop across a $0.01 \mathrm{ohm}, \pm 1$ per cent, 100-amp shunt resistor.

\section{Experiment HF-3}

\section{Operation}

This experiment was irradiated during BRR Cycles 118, 119, and 120. The total in-pile time was 783 hours.

At the beginning of the second cycle for this experiment, the gamma shield that had been used as a temporary measure was replaced with a more refined unit built as an open rectangular configuration that conformed closely to the geometry of the reactor space occupied. This shield installation permitted the positioning of the test chamber somewhat closer to the fuel elements than before.

The only abnormal events that occurred during the operation of $\mathrm{HF}-3$ were two auxiliary-heater failures and a diffusion-pump-heater failure. The first auxiliary heater failure occurred during Cycle 118. The failure was located above the top seal plate and therefore was repairable without disturbing the subassembly. The second auxiliary-heater failure occurred during Cycle 119. Since this was an internal failure, it was not repairable. Also, during Cycle 119, the diffusion-pump heater failed and required replacement.

At termination, 45 of the original 52 thermocouples incorporated into the experiment were apparently operating satisfactorily; the seven failures occurred at the beginning of the experiment.

\section{Temperature Levels}

Time-averaged specimen temperature levels for Experiment HF-3 are summarized in Table 4. As indicated, the specimens operated throughout the irradiation exposure in the 930 to $1030 \mathrm{~F}$ range. This pattern was maintained even after the one auxiliary heater was lost midway through Cycle 119 by applying additional heat input to the two remaining units.

The temperature performance of the experiment confirmed the heat-transfer design calculations which showed that the hexagonal configuration, with the specimens selectively arranged inside, would tend to even out the temperatures of specimens at different levels by radiation-heat-transfer interactions. 
TABLE 4. TIME-AVERA GED TEMPERATURE LEVELS FOR HF-3 EXPERIMENT

\begin{tabular}{lccc}
\hline & \multicolumn{3}{c}{ Temperature, $F$} \\
\cline { 2 - 4 } Specimen Type & Cycle 118 & Cycle 119(a) & Cycle 120 \\
\hline Friction samples & 965 & $980-960$ & 960 \\
Tensile specimens & 1000 & $1025-945$ & 940 \\
Coating specimens & 980 & $980-970$ & 975 \\
Braze specimens & 960 & $965-990$ & 935 \\
Connector halves & 1005 & 1020 & 1025 \\
Mated connector & 945 & $965-940$ & 940 \\
Cable samples & $960-980^{(b)}$ & $985-975$ & 975 \\
\hline \hline
\end{tabular}

(a) During Cycle 119, one of the auxiliary heaters failed, resulting in lower opera ting temperatures for some of the specimens for the remainder of the experiment.

(b) Variations in temperatures of the cable samples during Cycle 118 reflect heater power adjustments required to achieve optimum temperature patterns for the assembly.

\section{Vacuum Levels}

Vacuum levels in the $10^{-5}$ and $10^{-4}$ torr range were measured in the HF-3 system during the irradiation exposure. Difficulty wa experienced early in the operation with both the ionization gages located near the test section. However, the gage located out of the radiation zone near the pump permitted monitoring to continue throughout the exposure period.

A slight decrease in system vacuum level was noted near the end of the second cycle, and continued during the last reactor cycle. However, the limited amount of leak checking that could be accomplished failed to reveal a leak. Later, at disas sembly, it was discovered that the irrepairable heater had arced through its sheath just beneath the header plate. Thus, a gas leakage path was exposed through the ceramic insulation between the sheath and the heater element.

\section{Electrical Measurements}

Insulation resistance measurements as follows were performed continuously during the HF-3 experiments start-up and at 8-hour intervals thereafter.

(1) Cable coils - resistances between each wire and the shield and between the two wires. The resistance of each wire was also measured.

(2) Mated connector pair - resistance between six of the pins and the connector shell. Contact-drop measurements were also made on each of the pin pairs with 5-amp current.

(3) Unmated connector - resistances between the pins and the shell. 
The resistance measurements were made in essentially the same way and using the same equipment as in Experiment HF-1. Contact-drop measurements were made with a digital voltmeter at 5-amp constant current. As in HF-1, four-wire circuits to the header of the specimen containment chamber and dummy leads between the header and the specimen zone were utilized in the coil-resistance and the contact-drop measurements.

\author{
Experiment $\mathrm{HF}-4$
}

\title{
Operation
}

Experiment $H F-4$ was irradiated during BRR Cycles 129, 130, and 131. The total in-pile time was $842 \mathrm{hr}$. Operation during all cycles was quite routine except that controlled temperature cycling of certain components, as described below, was carried out. At the time of termination, 29 out of the 35 thermocouples in the experiment were apparently operating satisfactorily.

\section{Temperature Levels}

Time-averaged steady-state temperature levels for Experiment HF-4 are summarized in Table 5. In most cases, temperatures very close to those desired could be obtained by the zonal control of auxiliary heat input that wa available. As in HF -1 , the spool-temperature determinations were made on the basis of coil-resistance measurements.

TABIE 5. TIME-AVERAGED TEMPERATURE LEVELS FOR HF-4 EXPERIMENT

\begin{tabular}{lcrr}
\hline & \multicolumn{3}{c}{ Temperature, } \\
\cline { 2 - 4 } \multicolumn{1}{c}{ Specimen Type } & Cycle 129 & Cycle 130 & Cycle 131 \\
\hline Temperature sensor & 975 & 940 & 960 \\
Self-weld fixtures & 990 & 980 & 1000 \\
Connectors & 810 & 830 & 835 \\
TIMM circuits & 1035 & 1050 & 1045 \\
Insulation spools & 785 & 770 & 750 \\
Dimensional-stability samples & 995 & 1000 & 1000 \\
\end{tabular}

Controlled thermal cycling of the spools, connectors, and temperature sensor was carried out during the experiment. For the spools and connectors, the thermal cycle program was four per reactor cycle and one per shutdown period. For the temperature sensor, the program was one per day except when this operation interfered with the normal operation of the experiment. The cycling consisted of adjusting the temperature levels to approximately $100 \mathrm{~F}$ below the normal level by manipulation of the auxiliary heat input, performing the required monitoring at the reduced temperature, and returning to normal temperature operation. The sequences required approximately $3 \mathrm{hr}$ to complete. 
Vacuum Levels

Vacuum levels between $10^{-4}$ and 10-6 torr were measured at the test section during the HF-4 experiment. After the first 2 days of in-pile operation, the vacuum at the test section remained below $3 \times 10^{-5}$ torr and varied between $5 \times 10^{-6}$ and $1 \times 10^{-5}$ torr during the last cycle of the experiment.

Electrical Measurements

The following measurements were made every $4 \mathrm{hr}$ at the start-up of each reactor cycle of the HF-4 experiment and every $8 \mathrm{hr}$ once the measurements had settled into a definite pattern:

(1) Spools - insulation and coil resistances as was the case for the spools in Experiment $\mathrm{HF}-1$.

(2) Connectors - pin-to-shell insulation resistances as was the case for the unmated connectors in Experiment HF-3.

(3) Resistance temperature sensor - lead and element resistances. In addition, the temperatures sensed by the three thermocouples incorporated into the device upon delivery to Battelle were monitored by an internally compensated manual potentiometer to achieve the degree of accuracy of specimen temperature measurement desired.

(4) TIMM circuits - resistance of the resistors by current-voltagedrop determinations, voltage drops across and the current through the diodes at two supply voltages, and total leakage current of the parallel-connected capacitors. TIMM triodes were included in the package but a short in their measuring circuit precluded meaningful measurements.

With the exception of the resistance-temperature sensor and its leads, the resistances were determined by measuring the voltage drop at a known constant current, using a four-wire circuit connected at the capsule header. The temperature sensor resistance measurements were made with a five-dial Wheatstone Bridge. The leakage current was measured with a Keithley Model 210 Electrometer and Model 2008 Shunt.

Figure 13 illustrates the insulation-resistance measurement circuit utilized in Experiment $\mathrm{HF}-4$. The circuit was provided by Atomics International personnel. It is operated in the following manner. The value of shunt resistance $R_{\mathbb{s}}$ is selected from previous knowledge such that the voltage drop is between 0.0100 and $0.999 \mathrm{v}$. With $\mathrm{S}_{3}$ open and $\mathrm{S}_{2}$ in the "b" position, the power supply is adjusted so that the digital voltmeter reads $50.00 \pm 0.03 \mathrm{v}$. $S_{2}$ is then switched to the "a" position. The digital voltmeter is read 5 sec after $\mathrm{S}_{3}$ is closed. 


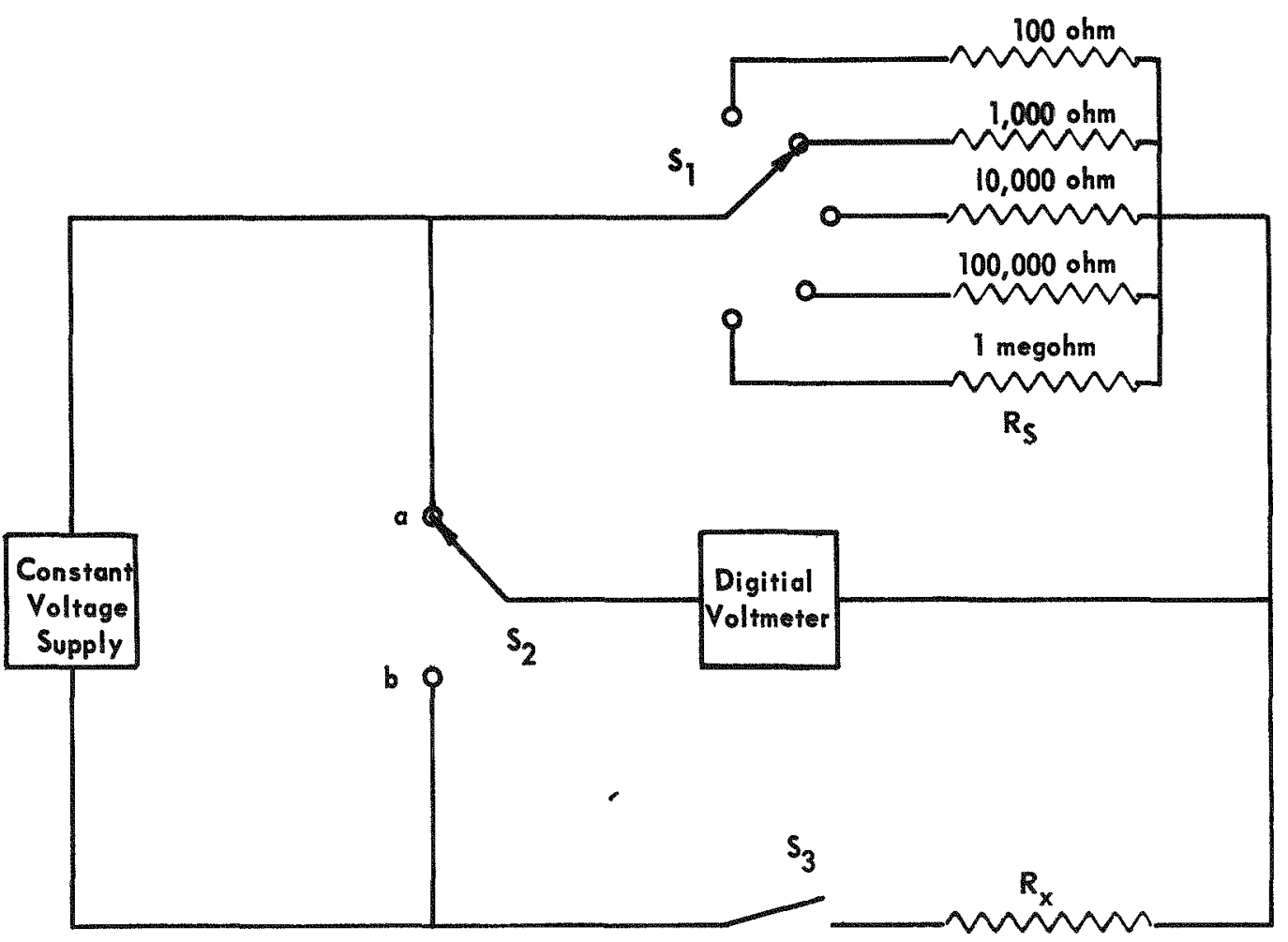

FIGURE 13. INSULATION RESISTANCE MEASURING CIRCUIT PROVIDED BY ATOMICS INTERNATIONAL FOR USE IN HF-4 EXPERIMENTS 
Summary of Specimen Radiation Exposures

Individual specimen exposures are listed in the Appendix. Neutron exposures greater than $0.5 \mathrm{Mev}$ arithmetically averaged over the test specimens were as follows:

$$
\begin{array}{ll}
\text { HF-1 (36-day exposure) } & 4.65 \times 10^{18} \mathrm{n} / \mathrm{cm}^{2} \\
\text { HF-2 (12-day exposure) } & 2.00 \times 10^{18} \mathrm{n} / \mathrm{cm}^{2} \\
\text { HF-3 (36-day exposure) } & 6.38 \times 10^{18} \mathrm{n} / \mathrm{cm}^{2} \\
\text { HF-4 (36-day exposure) } & 6.04 \times 10^{18} \mathrm{n} / \mathrm{cm}^{2}
\end{array}
$$

On the basis of the mock-up data, it was expected that the 36-day exposure level would be approximately $1.5 \times 1019 \mathrm{n} / \mathrm{cm}^{2}$. Thus, the actual neutron exposures were much lower than predicted from the mock-up data. Perturbation effects of the specimens themselves may have been partially responsible for this situation. Probably more important, however, is the exposure loss resulting from the gamma shield that was adopted as an experimental necessity. This shield effect seems particularly noticeable in the case of Experiment HF-1. In this experiment, the temporary design of the shield prevented location of the test chamber as close to the reactor core as was the case with the other shield designs used afterward. However, none of the shields permitted the test section to be located as close to the core face as was the mock-up facility. Because of the steep flux gradient at the front core face, these small differences in test-section location (actually, distances of $2 \mathrm{in}$. or less from the core face) could be the major factor contributing to the reduced neutron exposures.

SJ B/WGR/JHS/HTG/BPF:js 


\section{APPENDIX}

RADIATION EXPOSURES OF INDIVIDUAL COMPONENTS OF EXPERIMENTS $H F-1,-2,-3$, AND -4 
The neutron and gamma exposures of the individual components are listed in Tables $A-1$ through A-4. Figures $A-1$ through $A-4$ show the specimen configuration utilized for the various experiments.

The neutron exposures are broken down into four groups: Group I is the thermalneutron exposure (0-0.4 ev); Group II is the resonance-neutron exposure (0.017-0.1 Mev); Group III is the fast-neutron exposure from 0.1 to $0.5 \mathrm{Mev}$ and was obtained by subtracting the fast-neutron exposure above $0.5 \mathrm{Mev}$ from the total fast exposure; and Group IV is the fast-neutron exposure above $0.5 \mathrm{Mev}$. 
TABLE A-1. EXPERIMENT HIGH FLUX 1, NEUTRON AND GAMMA EXPOSURES

\begin{tabular}{|c|c|c|c|c|c|}
\hline Component & $\begin{array}{c}\text { Group Is } \\
10^{16} \mathrm{~N} / \mathrm{Cm}^{2}\end{array}$ & $\begin{array}{c}\text { Group II, } \\
10^{17} \mathrm{~N} / \mathrm{Cm}^{2}\end{array}$ & $\begin{array}{l}\text { Group III, } \\
10^{17} \mathrm{~N} / \mathrm{Cm}^{2}\end{array}$ & $\begin{array}{c}\text { Group IV, } \\
10^{18} \mathrm{~N} / \mathrm{Cm}^{2}\end{array}$ & $\begin{array}{c}\text { Gamma Exposure } \\
10^{10} \mathrm{R}\end{array}$ \\
\hline Magnet-3 & 8.03 & 4.32 & 2.88 & 1.94 & 3.21 \\
\hline$W-112$ & 8.35 & 8.51 & 7.04 & 4,74 & 4.14 \\
\hline$W-2$ & 8.62 & 8.93 & 8.32 & 5.60 & 5.06 \\
\hline$W-111$ & 9.28 & 8.63 & 7.15 & 4.80 & 5.07 \\
\hline$W-1$ & 8.30 & 7.76 & 5.98 & 4.02 & 5.07 \\
\hline Magnet-4 & 6.61 & 4.30 & 2.94 & 1.98 & 3.79 \\
\hline B-107 & 6.04 & 8.12 & 5.77 & 3.88 & 4.12 \\
\hline$B-106$ & 8.04 & 9.94 & 8.54 & 5.74 & 5.35 \\
\hline$W-3$ & 7.39 & 10.4 & 8.57 & 5.76 & 6.57 \\
\hline$W-113$ & 8.85 & 11.4 & 10.99 & 7.39 & 6.57 \\
\hline$B-105$ & 6.23 & 6.61 & 4.73 & 3.18 & 5.02 \\
\hline$B-115$ & 5.84 & 9.11 & 6.36 & 4.28 & 5.25 \\
\hline$B-114$ & 7.38 & 11.5 & 10.3 & 6.91 & 8.40 \\
\hline B-113 & 7.83 & 11.2 & 10.3 & 6.90 & 8.40 \\
\hline$B-111$ & 6.45 & 7.36 & 6.09 & 4.10 & 8.40 \\
\hline$B-110$ & 5.07 & 7.61 & 4.19 & 2.82 & 6.05 \\
\hline A & 6.81 & 10.2 & 8.43 & 5.67 & 6.72 \\
\hline G & 7.84 & 11.3 & 10.3 & 6.92 & 8.40 \\
\hline $\mathrm{F}$ & 7.82 & 9.73 & 8.04 & 5.41 & 8.40 \\
\hline$s-1$ & 5.30 & 8.19 & 5.49 & 3.69 & 4.88 \\
\hline$S-2$ & 5.30 & 8.19 & 5.49 & 3.69 & 4.88 \\
\hline$S-3$ & 6.31 & 7.97 & 7.29 & 4.90 & 6.51 \\
\hline$S-10$ & 6.31 & 8.56 & 7.82 & 5.26 & 8.14 \\
\hline$S-11$ & 6.31 & 9.14 & 8.35 & 5.62 & 8.14 \\
\hline$S-12$ & 6.31 & 8.60 & 7.44 & 5.00 & 8.14 \\
\hline$V-5$ & 6.31 & 9.14 & 8.35 & 5.62 & 8.14 \\
\hline$V-6$ & 4.71 & 8.60 & 7.44 & 5.00 & 8.14 \\
\hline$v-7$ & 4.71 & 8.06 & 6.53 & 4.39 & 5.59 \\
\hline$I-1$ & 5.30 & 8.46 & 8.40 & 3.31 & 4.88 \\
\hline$I-2$ & 5.30 & 8.19 & 5.49 & 3.69 & 6.51 \\
\hline$I-3$ & 6.31 & 7.79 & 7.29 & 4.90 & 6.51 \\
\hline 14 & 4.71 & 8.06 & 6.53 & 4.39 & 5.59 \\
\hline 15 & 4.71 & 7.40 & 4.92 & 3.31 & 5.59 \\
\hline 16 & 4.71 & 7.40 & 4.92 & 3.31 & 5.59 \\
\hline
\end{tabular}


TABLE A-2 EXPERIMENT HIGH FLUX 2 NEUTRON AND GAMMA EXPOSURES

\begin{tabular}{|c|c|c|c|c|c|}
\hline & $\begin{array}{l}\text { Group I, } \\
1017 \mathrm{~N} / \mathrm{Cm}^{2}\end{array}$ & $\begin{array}{c}\text { Group II } \\
10^{17} \mathrm{~N} / \mathrm{Cm}^{2}\end{array}$ & $\begin{array}{l}\text { Group III, } \\
10^{18} \mathrm{~N} / \mathrm{Cm}^{2}\end{array}$ & $\begin{array}{c}\text { Group IV, } \\
10^{18} \mathrm{~N} / \mathrm{Cm}^{2}\end{array}$ & $\begin{array}{c}\text { Gamma Exposure, } \\
10^{10} \mathrm{R}\end{array}$ \\
\hline \multicolumn{6}{|l|}{ Strips No. 1 and 2} \\
\hline 1 to 2 -in. section (a) & 1.41 & 3.85 & 0.23 & 1.54 & 1.09 \\
\hline 3 to 4 in. section & 1.38 & 4.05 & 0.26 & 1.75 & 1.23 \\
\hline 5 to 6 -in. section & 1.35 & 4.05 & 0.27 & 1.83 & 1.40 \\
\hline 7 to 8 -in. section & 1.34 & 4.00 & 0.28 & 1.83 & 1.57 \\
\hline \multicolumn{6}{|l|}{ Strips No. 3 and 4} \\
\hline 1 to 2 -in. section (a) & 1.74 & 5.56 & 0.33 & 2.23 & 1.39 \\
\hline 3 to 4 -in. section & 1.64 & 5.76 & 0.37 & 2.49 & 1.55 \\
\hline 5 to 6 -in. section & 1.65 & 5.54 & 0.38 & 2.49 & 1.72 \\
\hline 7 to 8 -in. section & 1.52 & 5.47 & 0.37 & 2.51 & 1.89 \\
\hline \multicolumn{6}{|l|}{ Strips No. 5 and 6} \\
\hline 1 to 2 -in. section $(a)$ & 1.40 & 4.05 & 0.25 & 1.62 & 1.27 \\
\hline 3 to 4 -in. section & 1.41 & 4.14 & 0.27 & 1.78 & 1.46 \\
\hline 5 to 6 -in. section & 1,40 & 4.33 & 0.29 & 1.95 & 1.67 \\
\hline 7 to 8 -in. section & 1.33 & 4.21 & 0.29 & 1.93 & 1.86 \\
\hline
\end{tabular}

(a) Sections starting at bottom of each setup, $i, e, 1$ to 2-in, section designates bottom 2 in. of strip, 3 to $4-$ in. section designates next adjacent 2 -in. section, etc. 
TABLE A-3. EXPERIMENT HIGH FLUX-3 NEUTRON AND GAMMA EXPOSURES

\begin{tabular}{|c|c|c|c|c|}
\hline & $\begin{array}{c}\text { Group II, } \\
10^{18} \mathrm{~N} / \mathrm{Cm}^{2} \\
\end{array}$ & $\begin{array}{c}\text { Group III, } \\
10^{18} \mathrm{~N} / \mathrm{Cm}^{2} \\
\end{array}$ & $\begin{array}{r}\text { Group IV, } \\
10^{18} \mathrm{~N} / \mathrm{cm}^{2} \\
\end{array}$ & $\begin{array}{c}\text { Gamma Exposure, } \\
10^{10} \mathrm{R} \\
\end{array}$ \\
\hline \multicolumn{5}{|l|}{ Friction Specimens } \\
\hline 212 & 1.22 & 0.65 & 5.30 & 2.51 \\
\hline S1a & 1.39 & 0.83 & 6.72 & 2.93 \\
\hline 297 & 1.56 & 0.95 & 7.67 & 3.28 \\
\hline 200 & 1.60 & 0.98 & 7.92 & 3.58 \\
\hline 213 & 1.57 & 1.03 & 8.32 & 2.95 \\
\hline 295 & 1.79 & 1.26 & 10.22 & 3.44 \\
\hline 290 & 1.89 & 1.35 & 10.95 & 3.89 \\
\hline 194 & 1.90 & 1.31 & 10.60 & 4.28 \\
\hline 170 & 1.22 & 0.73 & 5.88 & 2.28 \\
\hline S1b & 1.42 & 0.99 & 8.01 & 2.68 \\
\hline 298 & 1.59 & 1.14 & 9.22 & 3.05 \\
\hline 195 & 1.64 & 1.16 & 9.35 & 3.38 \\
\hline 169 & 1.31 & 0.78 & 6.32 & 2.71 \\
\hline 99 & 1.46 & 1.02 & 8.23 & 3.25 \\
\hline 296 & 1.62 & 1.16 & 9.38 & 3.70 \\
\hline 289 & 1.67 & 1.18 & 9.54 & 4.17 \\
\hline 199 & 1.65 & 1.11 & 8.94 & 4.55 \\
\hline \multicolumn{5}{|l|}{ Small Connectors } \\
\hline 4 & 1.61 & 0.66 & 5.34 & 2.91 \\
\hline 5 & 1.54 & 0.65 & 5.24 & 2.84 \\
\hline \multicolumn{5}{|l|}{ Emissivity Buttons } \\
\hline$E-1$ & 1.41 & 0.60 & 4.84 & 2.66 \\
\hline$E-2$ & 1.47 & 0.63 & 5.07 & 2.65 \\
\hline$E-3$ & 1.55 & 0.66 & 5.32 & 2.64 \\
\hline$E-4$ & 1.38 & 0.56 & 4.77 & 2.57 \\
\hline$E-5$ & 1.44 & 0.62 & 5.00 & 2.56 \\
\hline $\mathbf{E}-6$ & 1.51 & 0.65 & 5.22 & 2.56 \\
\hline \multicolumn{5}{|l|}{ Mated Connector } \\
\hline $\begin{array}{l}\text { No number } \\
\text { designation }\end{array}$ & 1.22 & 0.50 & 4.07 & 2.12 \\
\hline \multicolumn{5}{|l|}{ Cable Coils } \\
\hline$C-3$ & 1.35 & 0.83 & 6.74 & 2.85 \\
\hline$C-1$ & 1.34 & 0.82 & 6.68 & 2.71 \\
\hline$C-4$ & 1.29 & 0.79 & 6.35 & 2.52 \\
\hline$C-2$ & 1.19 & 0.71 & 5.75 & 2.34 \\
\hline \multicolumn{5}{|l|}{ Braze Specimens } \\
\hline 17 & 0.93 & 0.49 & 3.94 & 1.97 \\
\hline 18 & 1.03 & 0.54 & 4.37 & 1.96 \\
\hline$s-13$ & 1.13 & 0.59 & 4.80 & 1.94 \\
\hline \multicolumn{5}{|l|}{ Tensile Specimens } \\
\hline 2 & 1.09 & 0.52 & 4.17 & 2.10 \\
\hline 7 & 1.04 & 0.49 & 4.01 & 2.10 \\
\hline 12 & 1.01 & 0.48 & 3.86 & 2.11 \\
\hline 10 & 1.24 & 0.65 & 5.30 & 2.57 \\
\hline 9 & 1.18 & 0.62 & 5.03 & 2.47 \\
\hline 15 & 1.13 & 0.60 & 4.81 & 2.43 \\
\hline 11 & 1.20 & 0.60 & 5.12 & 2.76 \\
\hline 13 & 1.15 & 0.60 & 4.90 & 2.77 \\
\hline 14 & 1.11 & 0.58 & 4.72 & 2.78 \\
\hline 1 & 1.73 & 0.91 & 7.37 & 2.99 \\
\hline 6 & 1.51 & 0.79 & 6.43 & 2.73 \\
\hline 5 & 1.76 & 0.93 & 7.51 & 3.10 \\
\hline 8 & 1.55 & 0.81 & 6.59 & 2.47 \\
\hline 3 & 1.52 & 0.72 & 5.84 & 2.56 \\
\hline 4 & 1.34 & 0.64 & 5.14 & 2.07 \\
\hline
\end{tabular}


TABLE A-4. EXPERIMENT HIGH FLUX-4 NEUTRON AND GAMMA EXPOSURES

\begin{tabular}{|c|c|c|c|c|c|}
\hline & $\begin{array}{c}\text { Group I, } \\
10^{17} \mathrm{~N} / \mathrm{Cm}^{2} \\
\end{array}$ & $\begin{array}{c}\text { Group II, } \\
10^{18 \mathrm{~N} / \mathrm{Cm}^{2}} \\
\end{array}$ & $\begin{array}{l}\text { Group III, } \\
10^{17} \mathrm{~N} / \mathrm{Cm}^{2} \\
\end{array}$ & $\begin{array}{c}\text { Group IV, } \\
10^{18} \mathrm{~N} / \mathrm{Cm}^{2} \\
\end{array}$ & $\begin{array}{c}\text { Gamma Exposure, } \\
10^{10} \mathrm{R} \\
\end{array}$ \\
\hline \multicolumn{6}{|c|}{ Spools Located in High Flux Zone } \\
\hline $\mathrm{S} 2$ & 8.32 & 1.62 & 11.6 & 8.90 & 1.73 \\
\hline S3 & 6.56 & 1.58 & 10.8 & 8.22 & 1.70 \\
\hline S4 & 8.16 & 1.53 & 9.9 & 7.54 & 1.70 \\
\hline S5 & 7.69 & 1.45 & 9.3 & 7.16 & 1.70 \\
\hline $\mathrm{P} 7$ & 7.16 & 2.10 & 8.1 & 6.24 & 1.47 \\
\hline P3 & 6.64 & 2.74 & 6.9 & 5.31 & 1.47 \\
\hline $\mathrm{P} 4$ & 5.79 & 1.06 & 5.9 & 4.42 & 1.47 \\
\hline P5 & 6.34 & 1.31 & 5.7 & 4.32 & 1.42 \\
\hline \multicolumn{6}{|l|}{ Timm Circuits } \\
\hline Diodes & 7.35 & 1.18 & 7.5 & 5.71 & 1.54 \\
\hline Triodes & 7.35 & 1.57 & 9.9 & 7.62 & 1,54 \\
\hline Resistors & 7.35 & 1.40 & 8.9 & 6.81 & 1. 54 \\
\hline Capacitors & 7.35 & 1.05 & 6.6 & 5.10 & 1.54 \\
\hline \multicolumn{6}{|c|}{ Dimensional Stability Samples } \\
\hline $\mathrm{DS}-\mathrm{C} 1$ & 8.12 & 1.42 & 9.9 & 7.55 & 1.71 \\
\hline $\mathrm{DS} \sim \mathrm{C} 3$ & 8.12 & 1.39 & 9.5 & 7.33 & 1.68 \\
\hline DS-C5 & 7.60 & 1.33 & 9.1 & 6.91 & 1.65 \\
\hline $\mathrm{DS}=\mathrm{T} 10$ & 7.60 & 1.57 & 10.5 & 8.02 & 1.63 \\
\hline DS-T6 & 4.93 & 1.02 & 5.6 & 4.29 & 1.47 \\
\hline $\mathrm{DS}=\mathrm{S} 4$ & 4.93 & 1.03 & 5.6 & 4.30 & 1.45 \\
\hline DS-S5 & 5.28 & 1.09 & 5.9 & 4.55 & 1.42 \\
\hline DS $-S 6$ & 5.28 & 1.09 & 5.8 & 4.45 & 1.40 \\
\hline DS-T18 & 9.04 & 1.26 & 8.5 & 6.54 & 1.54 \\
\hline DS-T19 & 9.04 & 1.32 & 8.8 & 6.79 & 1.52 \\
\hline $\mathrm{DS}-\mathrm{T} 4$ & 8.89 & 1.18 & 7.9 & 6.02 & 1.50 \\
\hline DS T5 & 8.89 & 1.02 & 6.6 & 5.03 & 1.46 \\
\hline \multicolumn{6}{|c|}{ Self-Welding Fixtures } \\
\hline SWF -3 & 8.81 & 1.13 & 5.5 & 4.19 & 1.31 \\
\hline$S W F=4$ & 7.97 & 1.00 & 4.9 & 3.57 & 1.24 \\
\hline$S W F-5$ & 8.99 & 1.28 & 6.5 & 5.02 & 1.42 \\
\hline \multicolumn{6}{|l|}{ Temperature Sensor } \\
\hline TS -1 & 9.60 & 1.52 & 7.5 & 5.82 & 1.46 \\
\hline \multicolumn{6}{|l|}{ Connectors } \\
\hline 3 & 7.69 & 1.45 & 9.3 & 7.16 & 1.70 \\
\hline \multirow[t]{2}{*}{6} & 7.16 & 2.10 & 8.1 & 6.24 & 1.46 \\
\hline & $\begin{array}{c}\text { Group I, } \\
10^{17} \mathrm{~N} / \mathrm{Cm}^{2} \\
\end{array}$ & $\begin{array}{l}\text { Group } \mathrm{II}^{(\mathrm{a})} \\
10^{15} \mathrm{~N} / \mathrm{Cm}^{2} \\
\end{array}$ & $\begin{array}{c}\text { Group III } \\
10^{16} \mathrm{~N} / \mathrm{Cm}^{2} \\
\end{array}$ & $\begin{array}{c}\text { Group IV, } \\
10^{16} \mathrm{~N} / \mathrm{Cm}^{2} \\
\end{array}$ & $\begin{array}{l}\text { Gamma Exposure }{ }^{(\mathrm{a})}, \\
10^{9} \mathrm{R} \\
\end{array}$ \\
\hline \multicolumn{6}{|c|}{ Spools Located in Low Flux Zone } \\
\hline$s-1$ & 2.77 & 1.0 & 0.61 & 4.56 & 1.38 \\
\hline$P-6$ & 2.85 & 1.0 & 0.60 & 4.50 & 1.38 \\
\hline
\end{tabular}

(a) Estimated values. 

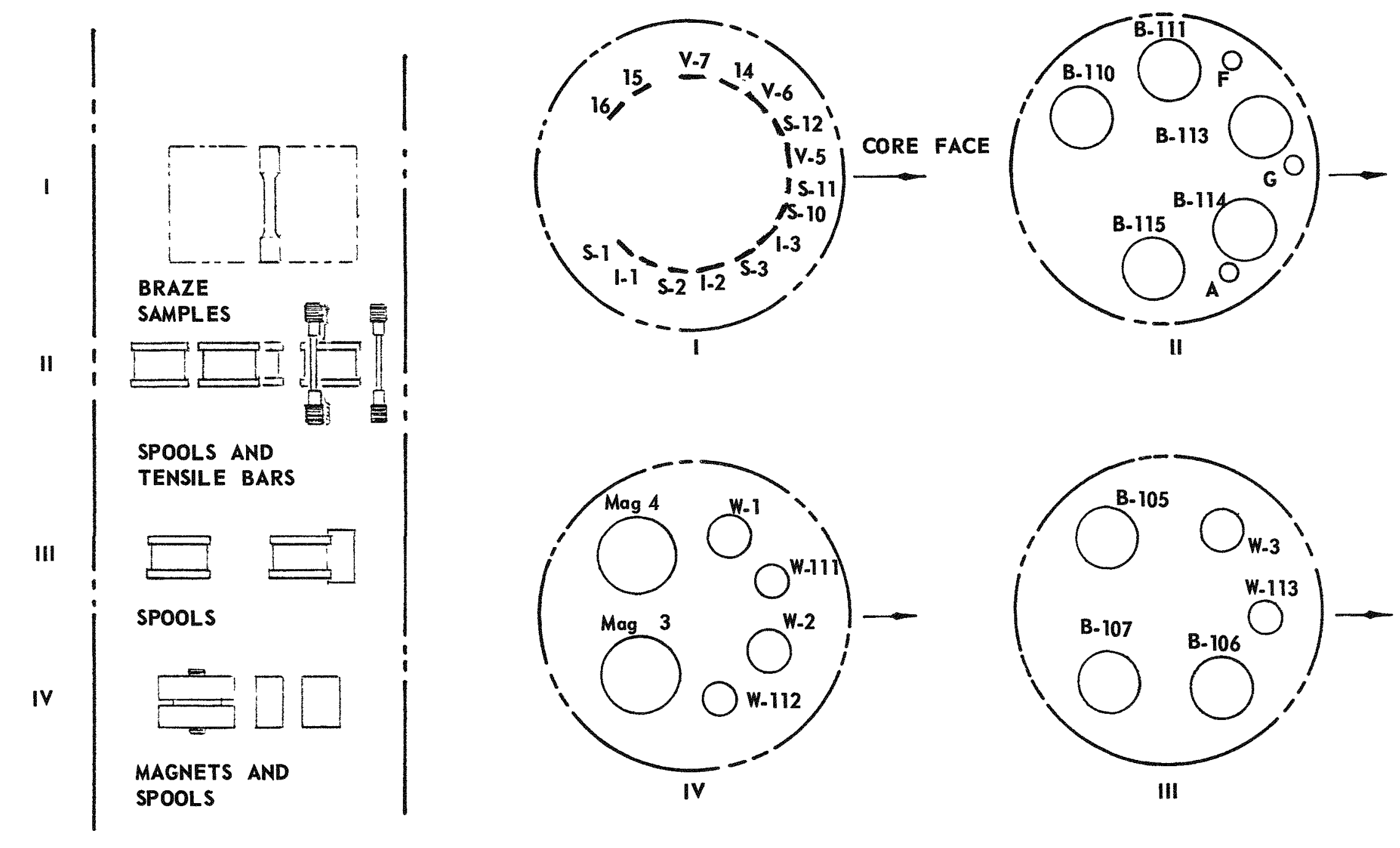

FIGURE A-1. EXPERIMENT HIGH FLUX I SPECIMEN CONFIGURATION 

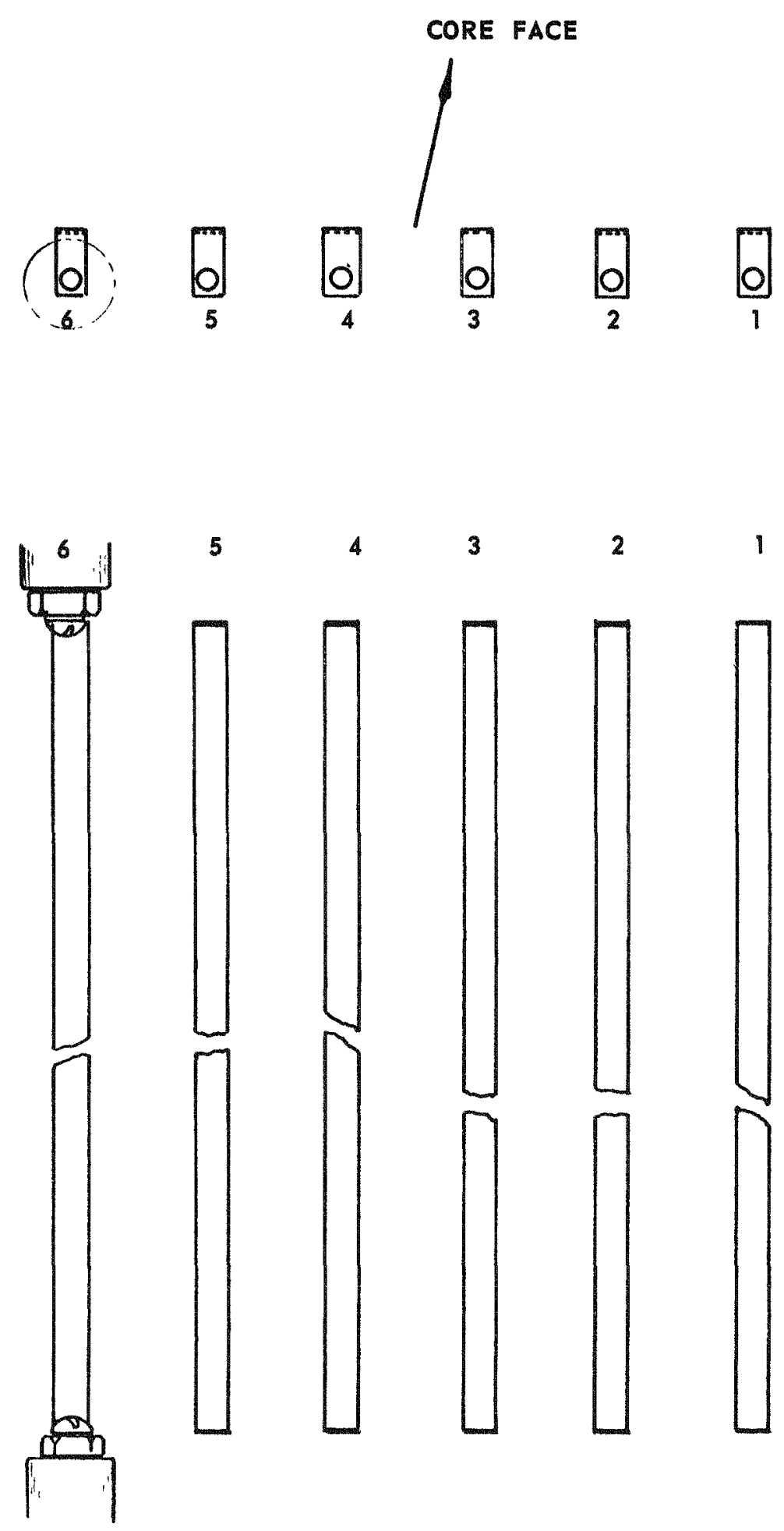

FIGURE A-2. EXPERIMENT HIGH FLUX 2 EMISSIVITY.STRIP CONFIGURATION 

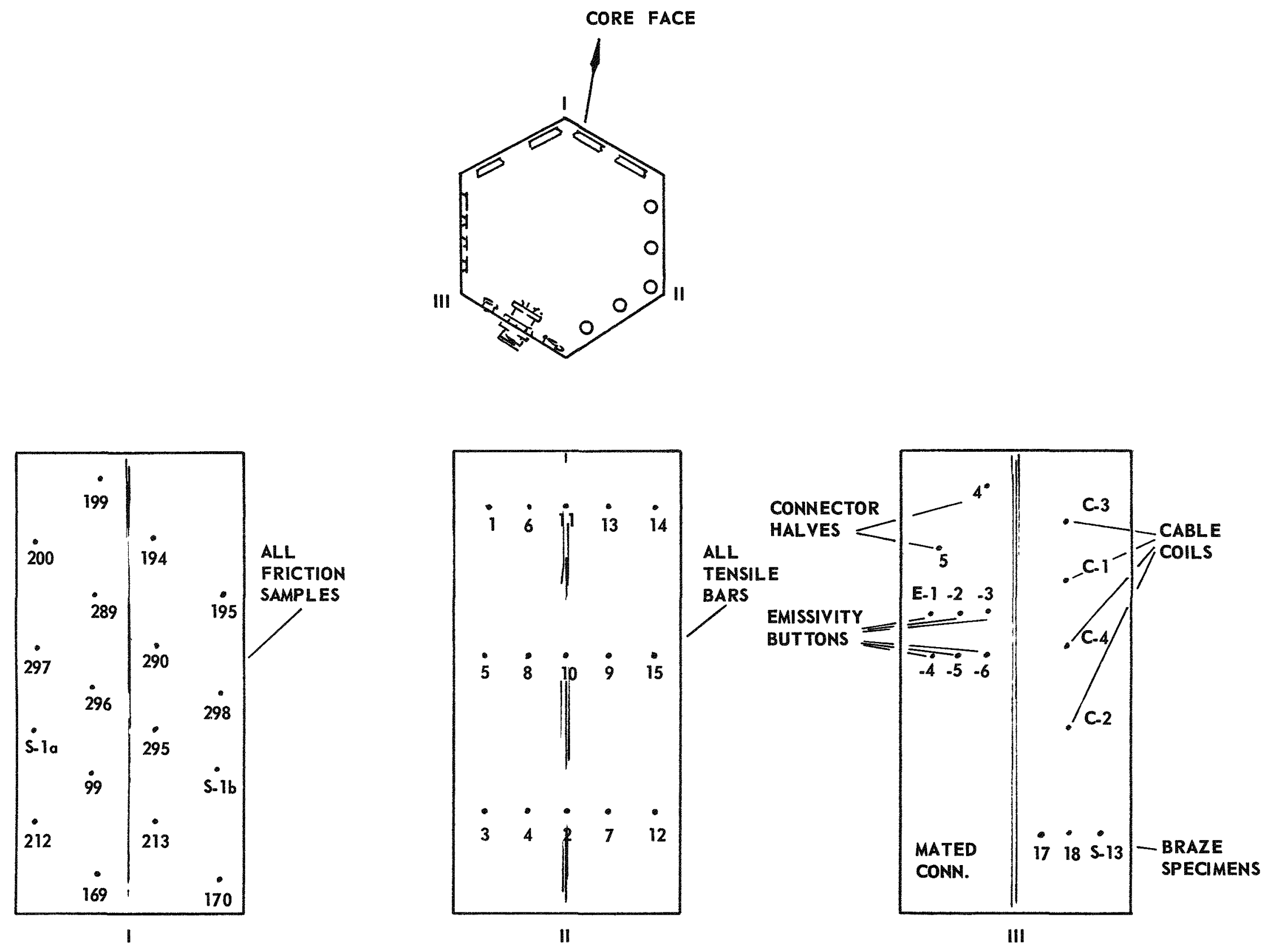

FIGURE A-3. EXPERIMENT HIGH FLUX 3 SPECIMEN CONFIGURATION 


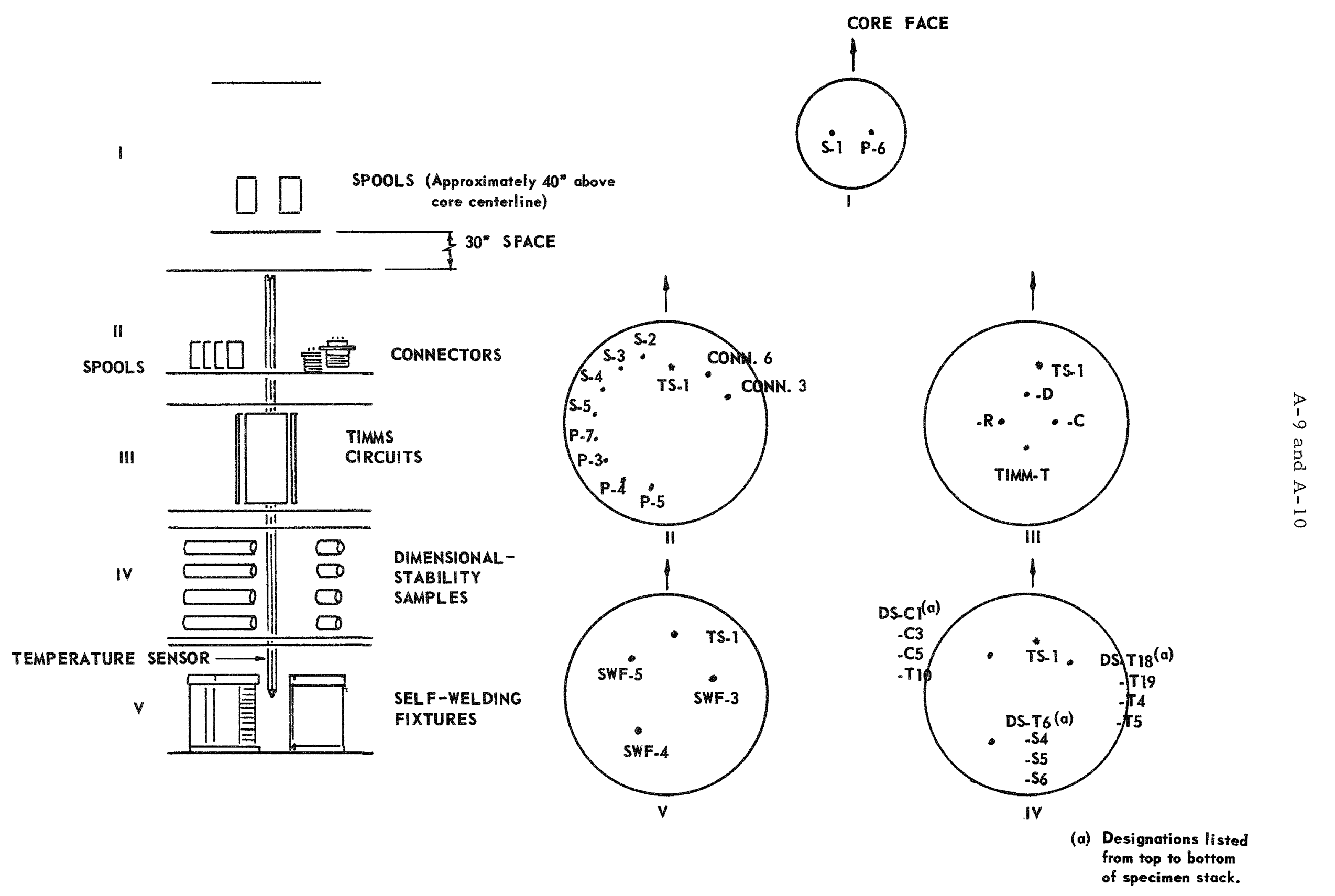

FIGURE A-4. EXPERIMENT HIGH FLUX 4 SPECIMEN CONFIGURATION 